\title{
Las competencias de la Comunidad Autónoma de Andalucía sobre Asociaciones ${ }^{1}$
}

\author{
Manuel Ángel Rodríguez Portugués \\ Becario FPI Universidad de Córdoba
}

I. INTRODUCCIÓN. II. LAS COMPETENCIAS MATERIALES DE LA COMUNIDAD AUTÓNOMA DE ANDALUCÍA SOBRE ASOCIACIONES. 2.1. El "carácter" (las finalidades) de las asociaciones. a) La atención a la finalidad como criterio para delimitar el "carácter" de las asociaciones. b) Interpretación de la cláusula "y similares": la competencia autonómica como título competencial genérico sobre asociaciones. 2.2. El desarrollo de sus funciones "principalmente" en Andalucía. a) Las "funciones" de las asociaciones. b) El adverbio "principalmente". III. DELIMITACIÓN NEGATIVA DE LA COMPETENCIA AUTONÓMICA CON RESPECTO A OTROS TÍTULOS COMPETENCIALES DEL ESTADO: LA "NO EXCLUSIVIDAD" DE LA COMPETENCIA ANDALUZA SOBRE ASOCIACIONES. 3.1. El desarrollo del derecho fundamental de asociación por el Estado ex art. 81.1 CE. 3.2. Las competencias del Estado sobre las "condiciones básicas que garanticen la igualdad de todos los españoles en el ejercicio" del derecho de asociación (art. 149.1.1ํㅡㄹ $\mathrm{CE}$ ). 3.3. Las competencias del Estado sobre la "legislación civil" (art. 149.1.8 $\mathrm{aE}$ ): su casi total irrelevancia final. 3.4. La competencia del Estado sobre "registros e instrumentos públicos" (art. 149.1.8 $\mathrm{CE}$ ). 3.5. Otros títulos de competencia estatales concurrentes con el de las Comunidades Autónomas. 3.6. Las cláusulas residual y de suplencia a favor del Estado (art. 149.3 CE) en materia de asociaciones; las llamadas asociaciones "de ámbito estatal". IV. CONCLUSIÓN.

\section{INTRODUCCIÓN}

El art. 13.25 del Estatuto andaluz de Autonomía establece que la Comunidad Autónoma de Andalucía tiene "competencia exclusiva” sobre "asocia-

\footnotetext{
${ }^{1}$ Proyecto de Investigación BJU2000-0845 y Grupo de Investigación SEJ-196. Quiero agradecer muy especialmente a la Cátedra de Participación Ciudadana de la Universidad de Córdoba su inestimable ayuda, bajo cuyo impulso y apoyo se ha realizado este trabajo.
} 
ciones de carácter docente, cultural, artístico, benéfico-asistencial y similares, que desarrollen principalmente sus funciones" en el territorio de la propia Comunidad Autónoma ${ }^{2}$. El propósito del presente trabajo es delimitar hasta dónde alcanza en realidad esta competencia.

Ahora bien, la falta de desarrollo del derecho de asociación por Ley orgánica hasta fechas muy recientes; la existencia hasta entonces de una Ley de asociaciones inspirada en principios incompatibles por lo general con los inaugurados por la Constitución de 1978; el temprano desarrollo de aquel derecho y del régimen jurídico de las asociaciones por parte de algunas Comunidades Autónomas; una jurisprudencia constitucional escasa, vacilante y abstracta sobre la materia; y, finalmente, una doctrina desconcertada y dividida en ciertos puntos capitales, son los ingredientes necesarios para entender las dificultades con que habría de toparse cualquier estudio sobre la cuestión que nos ocupa.

En efecto, la tarea reviste cierta dificultad, no sólo por la complejidad inherente a la propia materia y al sistema de distribución de competencias de que es objeto ${ }^{3}$, sino también por una cierta situación de oscuridad circunstancial que ha imperado en este sector de nuestro Ordenamiento durante los últimos años. Por un lado, se ha suscitado un complicado debate doctrinal insólitamente prolongado en el tiempo, de cuya complejidad y duración es responsable en buena medida la tardanza del legislador estatal para desarrollar el derecho de asociación contenido en el art. 22 CE.

\footnotetext{
${ }^{2}$ En similares términos se pronuncian los Estatutos de Autonomía de Canarias (art. 30.7), Comunidad Valenciana (art. 31.23), Cataluña (art. 9.24), País Vasco (art. 10.13) y la Ley Orgánica 13/1982, de 10 de agosto, de Reintegración y Amejoramiento del Régimen Foral de Navarra (art. 44.19). El resto de Comunidades Autónomas tienen sólo la competencia "ejecutiva" (arts. 12.2 del Estatuto de Autonomía del Principado de Asturias, 26.2 del Estatuto de Autonomía para Cantabria, 11.Uno.13 del Estatuto de Autonomía de La Rioja, 12.Uno.1 del Estatuto de Autonomía para la Región de Murcia, 39.Uno.11 del Estatuto de Autonomía de Aragón, 39.2 del Estatuto de Autonomía de Castilla-La Mancha, 9.2 del Estatuto de Autonomía de Extremadura, 12.5 del Estatuto de Autonomía para las Illes Balears, 28.1.4 del Estatuto de Autonomía de la Comunidad de Madrid, 36.1 del Estatuto de Autonomía de Castilla y León, y art. 4 de la Ley orgánica 16/1995, de 27 de diciembre, de Transferencia de Competencias a la Comunidad Autónoma Gallega).

${ }^{3}$ La heterogénea atribución de competencias a las Comunidades Autónomas (Comunidades Autónomas con competencias "exclusivas" y Comunidades Autónomas con competencias "de ejecución"), junto a la pluralidad de títulos de competencia estatales concurrentes en la materia, hace enormemente compleja la construcción del cuadro final del sistema de distribución de competencias entre el Estado y las Comunidades Autónomas en materia de asociaciones. Así lo hace notar Germán Fernández Farreres, Derecho de Asociación. Comentarios a la Ley Orgánica 1/2002, de 22 de marzo (con Jesús González Pérez), Civitas, Madrid, 2002, p. 493.
} 
Hasta hace muy poco tiempo -en que ha tenido lugar la promulgación de la Ley Orgánica 1/2002, de 22 de marzo, Reguladora del Derecho de Asociación (en adelante, LORDA)-, las dos únicas Comunidades Autónomas que se habían lanzado a aprobar sus respectivas normas sobre asociaciones, en desarrollo de esa capacidad que los Estatutos de Autonomía les reconocen, habían sido País Vasco y Cataluña, con la Ley 3/1988, de 12 de febrero ${ }^{4}$, y la Ley $7 / 1997$, de 18 de junio $^{5}$, respectivamente. La primera de ellas se ha visto afectada por la importante STC 173/1998, de 23 de julio, que resolvió el recurso planteado en 1988 por el Gobierno de la Nación contra dicha Ley por invasión de competencias estatales. La Ley catalana, por su parte, se encuentra a la espera de otro pronunciamiento constitucional. La demora del legislador estatal, el debate constitucional originado en parte por las dos leyes autonómicas citadas (una de ellas pendiente aún de Sentencia, como acabamos de notar ${ }^{6}$ ), junto a la consiguiente inseguridad jurídica, son probablemente los factores que más han contribuido a disuadir a las Comunidades Autónomas para actuar sus competencias en la materia. Abstención legislativa que ha desbloqueado la reciente promulgación de la LORDA y cuyo primer efecto ha sido, sin duda, la nueva Ley 4/2003, de 28 de febrero, de Asociaciones de Canarias, barrunto acaso de un inminente proceso de producción legislativa autonómica sobre asociaciones.

Además, aquellas Comunidades Autónomas creyeron oportuno desarrollar su competencia en materia de asociaciones, en un intento de suplir la inactividad estatal y desplazar la antigua Ley 191/1964, tan contraria al espíritu de la Constitución de 1978 en muchos de sus extremos. Tarea nada fácil, pues exigía del legislador autonómico desplegar su actividad en el "vacío", a falta del necesario desarrollo de ese derecho fundamental por Ley orgánica. Esta circunstancia explica la falta de unidad en la doctrina anterior que se ocupó de estas cuestiones, así como las inevitables abstracciones que padece la doctrina contenida en la citada STC 173/1998.

De todas estas dificultades nos iremos haciendo eco a lo largo de las páginas que siguen. Bástenos por ahora decir que, para el objetivo que nos hemos trazado -el estudio de las competencias de la Comunidad Autónoma de

${ }^{4}$ BO País Vasco de 1 de marzo de 1988, núm. 42.

${ }^{5}$ DO Generalitat de Catalunya de 1 de julio de 1997, núm. 2423.

${ }^{6}$ La LORDA es objeto actualmente, además, del Recurso de inconstitucionalidad número 3974-2002, promovido por el Parlamento de Cataluña (BOE de 22 de noviembre, núm. 280). 
Andalucía sobre asociaciones-, analizaremos en primer lugar la competencia material de la Comunidad Autónoma, es decir, el ámbito de la competencia respecto a su objeto, la realidad institucional a la que llamamos "asociación". Con esta cuestión tratamos de determinar si la competencia autonómica alcanza a todas las asociaciones o sólo a algunos tipos concretos de ellas, qué significa que dichas asociaciones han de desarrollar sus "funciones principalmente" en el ámbito de la Comunidad Autónoma, etc. Y en segundo lugar, abordaremos el estudio de la competencia desde una perspectiva negativa, o sea, qué otras competencias de titularidad estatal guardan estrecha relación con la materia asociativa. Desde este punto de vista, podremos constatar cómo la pretendida "exclusividad" de la competencia autonómica sobre asociaciones no es tal, sino que se encuentra intensamente condicionada por otros títulos competenciales del Estado destinados a modular decisivamente el régimen jurídico de las asociaciones andaluzas.

\section{LAS COMPETENCIAS MATERIALES DE LA COMUNIDAD AUTÓNOMA DE ANDALUCÍA SOBRE ASOCIACIONES}

\subsection{El "carácter" (las finalidades) de las asociaciones.}

\section{a) La atención a la finalidad como criterio para delimitar el "carácter" de las asociaciones}

El primer criterio de delimitación material que utiliza el Estatuto de $\mathrm{Au}-$ tonomía de Andalucía es la enumeración de una serie de caracteres que han de reunir las asociaciones para entender que caen bajo la competencia autonómica: "carácter docente, cultural, artístico, benéfico-asistencial y similares".

Dicha alusión al "carácter" de la asociación ha de entenderse referida a la finalidad que el propio ente se haya propuesto como su razón de ser. En efecto, de ningún otro elemento esencial del concepto de asociación es posible extraer el "carácter" de la misma. Deducir de otros elementos, como por ejemplo, del sustrato personal de la asociación, el carácter de la misma, nos llevaría a soluciones confusas respecto de otras competencias contenidas en el propio Estatuto de Autonomía. En efecto, si entendiéramos que el carácter de asociación docente o cultural corresponde a asociaciones compuestas únicamente de "docentes" o de "artistas", respectivamente, la competencia autonómica sobre asociaciones quedaría enormemente restringida, referida sólo posiblemente a asociaciones de "carácter profesional" o "corporativo", muy próxima a esa otra competencia que ya la Comunidad Autónoma ostenta sobre 
Corporaciones de Derecho público (art. 13.16 del Estatuto de Autonomía de Andalucía). En definitiva, hemos de entender que el "carácter" de las asociaciones a que se refiere la competencia autonómica se refiere a la "finalidad" de las mismas ${ }^{7}$.

\section{b) Interpretación de la cláusula "y similares": la competencia autonómica como título competencial genérico sobre asociaciones}

Otra importante duda, que sobre el alcance de las competencias materiales provoca la redacción del art. 13.25 Estatuto de Autonomía de Andalucía, viene determinada por la cláusula final "y similares". Esta expresión no constituye propiamente una cláusula de cierre ${ }^{8}$, sino más bien todo lo contrario, una locución que "abre" indefinidamente las competencias autonómicas a otras posibilidades, sin precisar cuáles. La postura del TC, sentada sobre todo en la STC 173/1998, responde negativamente a la cuestión de si este tipo de cláusulas -común, por lo demás, con los otros Estatutos de Autonomía a que hemos hecho referencia en la Introducción de este trabajo- incluyen todo género de asociaciones: estas competencias vía estatutaria tienen un límite que es inherente a la propia literalidad de los preceptos -viene a decir el TC-, ya que los Estatutos de Autonomía se refieren a un elenco concreto de asociaciones caracterizadas y diferenciadas por atender a unos fines y desarrollar unas actividades específicas ("asociaciones de carácter docente, cultural, artístico, benéfico-asistencial y similares"). Sólo sobre estos concretos tipos de asociaciones se extendería la facultad legislativa autonómica. Pero siendo verdad que la cláusula "y similares" no la convierte en indefinida o indeterminada ni en competencia genérica o residual sobre todas las asociaciones, matiza inmediatamente el TC esta afirmación mostrándose partidario de una interpretación amplia de dicha cláusula al objeto de incluir en la misma a las

\footnotetext{
7 En el mismo sentido, Pedro DE PABLO CONTRERAS, «Artículo 44. XIII. Asociaciones (apartado 19)», en Comentarios al Estatuto de Autonomía de la Comunidad Autónoma de Navarra, dir. por Juan Alfonso Santamaría Pastor, MAP, Madrid, 1992, p. 400, basándose en la legislación de asociaciones estatal inmediatamente anterior, que se refería a las "asociaciones dedicadas a fines asistenciales, educativos, culturales, deportivos o cualesquiera otros fines que tiendan a promover el bien común" cuando regulaba las asociaciones de «utilidad pública» (art. 4 de la Ley 191/1964, de 24 de diciembre). También acude a un argumento similar Eduardo RocA RocA, "Artículo 13.25: Fundaciones y Asociaciones», en Comentarios al Estatuto de Autonomía de Andalucía, dir. por Santiago Muñoz Machado, Ministerio de Administraciones Públicas/Instituto de Estudios de Administración Local, Madrid, 1987, p. 274.

${ }^{8}$ Vid. Josep FERrer RIBA, «Fundaciones y Asociaciones», en Comentarios sobre el Estatuto de Autonomía de Cataluña, Vol. II, Institut d'Estudis Autonòmics, Barcelona, 1990, p. 141.
} 
asociaciones cuyos fines coincidan con otras competencias de la Comunidad Autónoma (por ejemplo, defensa de los consumidores y usuarios, o juventud) ${ }^{9}$. Esto último justificaría una interpretación amplia del elenco de asociaciones y, por tanto, una mayor intensidad de las competencias autonómicas en este punto.

En definitiva, y por lo que se refiere a esta cuestión, dados los términos tan amplios y ambiguos en que se pronuncia la doctrina constitucional reseñada, a efectos prácticos nada obsta a que la cláusula "y similares" sea interpretada como título competencial genérico "asociaciones". A fin de cuentas, la expresión "y similares" predicado de un conjunto heterogéneo de asociaciones (docentes, culturales, artísticas, benéficas, asistenciales) equivale, en nuestra opinión, a "ausencia de ánimo de lucro", dato sobre el que el ordenamiento ha hecho descansar tradicionalmente la distinción de las asociaciones stricto sensu de otros entes análogos — sociedades civiles y mercantiles, sobre todo. En definitiva, de este dato se infiere, por tanto, el alcance general de las competencias autonómicas sobre el género "asociaciones" y no restringidas a un número cerrado y limitado de ellas ${ }^{10}$. Ello es coherente, además, con las competencias que sobre otros entes asociativos de diversa naturaleza reserva la Constitución al Estado (sociedades civiles y mercantiles, susceptibles de entender incluidas en la "legislación mercantil" y "civil" ex art. 149.1 CE, en sus apartados $6^{\circ}$ y $8^{\circ}$, respectivamente) o a la propia Comunidad Autónoma andaluza en otros preceptos de su Estatuto de Autonomía (caso de las cooperativas -art. 13.20 de su Estatuto de Autonomía- ). En cualquier caso, la decisiva doctrina del TC según la cual caerían bajo la competencia autonómica aquellas asociaciones cuyos fines coincidan con otras competencias materiales de la Comunidad Autónoma (juventud, menores, medio ambiente, servicios sociales y asistenciales, defensa de los consumidores y usuarios...), justificaría

\footnotetext{
${ }^{9}$ En este misma dirección ya se había pronunciado el Consejo Consultivo de la Generalidad de Cataluña (Vid. Dictamen no 144 del Consejo Consultivo de la Generalitat de Catalunya, de 15 de marzo de 1988, en Dictámenes del Consejo Consultivo de ..., cit., p. 117) según el cual esta cláusula permite incluir bajo la competencia autonómica a las asociaciones deportivas. Efectivamente, razonaba el Consejo Consultivo, aunque en el art. 9.24 del Estatuto de Autonomía catalán no se mencionan expresamente, no parece que se pueda poner ningún obstáculo para considerarlas incluidas dentro de la genérica referencia con que se cierra el enunciado de finalidades ("y similares"), máxime cuando la misma Comunidad Autónoma ostenta competencias también sobre la materia deportiva, ámbito en el que se proyecta este específico tipo asociativo.

${ }^{10}$ Ésta es básicamente la opinión de Enrique Lucas Murillo de LA Cueva, Igualdad y autonomía : las competencias sobre asociaciones en la jurisprudencia constitucional, Civitas, Madrid, 1999, pp. 147 y ss.
} 
sobradamente la regulación que la Comunidad Autónoma andaluza ha acometido sobre determinados tipos asociativos. Así, en este sentido, revisten especial importancia las siguientes normas: el Decreto 68/1986, de 9 de abril, sobre constitución y funcionamiento de Asociaciones Juveniles en Andalucía ${ }^{11}$, dictado "a los efectos de la política de subvenciones y participación" (art. 1‥1); el Decreto $27 / 1988$, de 10 de febrero, por el que se regulan las asociaciones de padres de alumnos de centros docentes no universitarios en el ámbito de la Comunidad Autónoma de Andalucía ${ }^{12}$; y el Decreto 28/1988, de 10 de febrero, por el que se regulan las asociaciones de alumnos de los centros docentes no universitarios en el ámbito de la Comunidad Autónoma de Andalucía ${ }^{13}$. También en algunas leyes sectoriales se contienen ciertas normas sobre asociaciones, como por ejemplo, en la Ley 5/1985, de 8 de julio, de los Consumidores y Usuarios en Andalucía, cuyos artículos 25 a 32 regulan distintos extremos del régimen jurídico de las asociaciones de consumidores y usuarios. Sin embargo, la finalidad y el alcance de todas estas regulaciones son más limitados que los que la Comunidad Autónoma podría establecer desde su competencia en materia de asociaciones, pues se ciñen fundamentalmente a la potestad de fomento que la Comunidad Autónoma tiene sobre cada uno de aquellos sectores materiales ${ }^{14}$.

Es más, ningún obstáculo se opone a que la Comunidad andaluza opte por aprobar una Ley de carácter general sobre las asociaciones de que es competente sin mayores precisiones -al modo de las leyes vasca, catalana o canaria-, en lugar de ir aprobando normas concretas sobre tipos especiales de asociaciones. En este sentido, el TC ha declarado que ello constituye una lícita y concreta opción de técnica legislativa a la que también llegan las competencias "exclusivas" de la Comunidad Autónoma ${ }^{15}$.

\subsection{El desarrollo de sus funciones "principalmente" en Andalucía.}

Como sabemos, el art. 13.25 del Estatuto de Autonomía de Andalucía se refiere también a otra condición: que las asociaciones desarrollen sus "fun-

${ }^{11}$ BO Junta de Andalucía de 30 de abril de 1986, núm. 37.

12 BO Junta de Andalucía de 1 de marzo de 1988, núm. 17.

${ }^{13}$ BO Junta de Andalucía de 1 de marzo de 1988, núm. 17.

${ }^{14}$ Así se desprende de la STC 157/1992, pronunciamiento del que damos cuenta más adelante.

${ }^{15}$ Así lo estimó la STC 173/1998 respecto de la Ley vasca 3/1988, de 12 de febrero, de asociaciones $\left(\mathrm{FJ} 4^{\circ}\right)$. 
ciones principalmente" en Andalucía. Es necesario aclarar el significado de estas dos expresiones: a qué se refiere el Estatuto cuando habla de "funciones" desarrolladas por una asociación, y qué quiere decirse con el adverbio "principalmente".

\section{a) Las "funciones" de las asociaciones}

Con razón ha criticado la doctrina el uso de esta expresión, ya que en puridad jurídica y en términos generales, las asociaciones no desempeñan "funciones", sino que realizan "actividades" en la prosecución de los "fines" que los socios fundadores originariamente hayan señalado al ente en cuestión ${ }^{16}$.

Esta inadecuación resulta tanto más evidente cuanto más se la examina a la luz de los nuevos principios constitucionales que rigen el derecho de asociación. En efecto, la idea de "función" evoca la idea de "dependencia" o "subordinación", y por ello es más apropiada a la idea de "órgano" como ente inserto en un conjunto organizativo más amplio, en cuyo seno sí puede o debe cumplir unas funciones respecto de los fines perseguidos por aquel complejo organizativo más amplio en el que se integra y que es el que realmente tiene atribuidos unos fines (el Estado, una Administración concreta, etc.). Por ello, la aplicación del concepto "funciones" a las asociaciones no sólo es inadecuada desde un punto de vista simplemente teórico, sino que también resulta incompatible con la nueva concepción que el art. 22 de la Constitución de 1978 tiene de estos entes, a saber, como organizaciones no integradas en ninguna estructura de índole estatal o pública; dignas de protección respecto de toda injerencia de los poderes públicos; y fruto del ejercicio de un derecho de libertad al que nuestra Carta Magna asigna el carácter de fundamental.

Las soluciones han oscilado entre las que refieren dicha expresión a "actividad de cumplimiento del fin" y las que entienden que se trata de "actividad de gestión o administración" ${ }^{17}$. El criterio más correcto, efectivamente, sería entender "funciones" como desempeño de actos de gestión, pues en la realización de dichas actuaciones se condensa normalmente, si no lo más importante en términos existenciales o sociológicos, sí al menos lo más decisivo de la vida de una asociación desde el punto de vista jurídico.

\footnotetext{
16 Vid. Pedro De Pablo Contreras, «Artículo 44. XIII...», en Comentarios..., cit., p. 400.

17 Vid. Josep Ferrer RibA, «Fundaciones...», en Comentarios..., cit., p. 143.
} 


\section{b) El adverbio "principalmente"}

El desempeño de funciones en la Comunidad Autónoma de Andalucía por las asociaciones se acompaña en la redacción del precepto que nos ocupa del adverbio "principalmente". Se ha dicho que esta palabra atribuye una amplia discrecionalidad tanto administrativa como judicial en última instancia ${ }^{18}$. Nosotros vemos preferible técnicamente, sin embargo, calificarla como concepto jurídico indeterminado ${ }^{19}$. Y ello porque no estamos, en efecto, ante un criterio que permita a la Administración andaluza, llegado el caso, decidir la aplicación o no del Derecho autonómico a una asociación según lo que sea más conveniente para los intereses públicos, sino ante un criterio que atribuye competencias a la Comunidad $\mathrm{Au}$ tónoma andaluza sobre asociaciones cuando se dé la única condición de que éstas desarrollen sus funciones "principalmente" en el ámbito territorial de aquélla.

La dificultad estriba, sin embargo, en determinar cuándo se da esa "principalidad" en el desarrollo de dichas funciones. Como oportunamente ha destacado la doctrina, se trata de una expresión excesivamente vaga, muy difícil de precisar en su aplicación al caso concreto ${ }^{20}$. ¿Cómo medir y qué proporción aplicar a los fines o a las actividades de la asociación para saber si éstos se llevan a cabo "principalmente" en la Comunidad Autónoma de que se trate?

Algunos Reales Decretos de Transferencia han interpretado dicho criterio como la exigencia acumulativa de domicilio y desarrollo de funciones principalmente en la Comunidad Autónoma. Es el caso, precisamente, del RD 304/1985, de 6 de febrero, de Traspaso de funciones y servicios del Estado en materia de Asociaciones a la Comunidad Autónoma de Andalucía, cuyo Anexo I atribuye a la Comunidad Autónoma la inscripción en el Registro de asociaciones de aquellas que desarrollen sus funciones en Andalucía y que "tengan establecido domicilio en el territorio de la misma" ${ }^{21}$. Sin embargo, además de

18 Vid. Josep FERRER RIBA, «Fundaciones...», en Comentarios..., cit., p. 145.

19 Así, José Ignacio López GonzÁlez, «Título I. Competencias de la Comunidad Autónoma. Artículo 13», en Comentarios al Estatuto de Andalucía, Instituto García Oviedo/Universidad de Sevilla, Sevilla, 1981, p. 92; y Eduardo RocA RoCA, «Artículo 13.25...», en Comentarios..., cit., p. 273.

${ }^{20}$ Sobre los principales interrogantes que provocan dichas previsiones, vid. Pedro DE PABLO Contreras, «Artículo 44. XIII...», en Comentarios..., cit., pp. 400 y 401.

21 Otros ejemplos de lo mismo son el RD 225/1986, de 24 de enero, de Traspaso de servicios de la Administración del Estado a la Comunidad Foral de Navarra en materia de asociaciones, y el RD 3526/1981, de 29 de diciembre, de Traspaso de servicios de la Administración del Estado a la Generalidad de Cataluña en materia de asociaciones. 
añadir injustificadamente un requisito más (el del domicilio) al que ya exigen los Estatutos (el desarrollo de funciones), el TC tiene dicho que estos Reales Decretos de Transferencia reflejan tan sólo el criterio interpretativo de las Comisiones mixtas que los elaboran, y no pueden prevalecer sobre las previsiones constitucionales y estatutarias correspondientes ${ }^{22}$.

Por su parte, tampoco los legisladores autonómicos que se han pronunciado hasta la fecha son de gran utilidad: la Ley de Canarias 4/2003, de 28 de febrero, de asociaciones, se remite sin más precisiones a lo dispuesto en su Estatuto de Autonomía (art. 1.1); la Ley del País Vasco 3/1988, de 12 de febrero, de asociaciones, después de remitirse también a lo dispuesto en su Estatuto de Autonomía, establece que "se entenderá, en todo caso, que se trata de Asociaciones que desarrollarán sus funciones principalmente en el País Vasco cuando así lo digan sus Estatutos"(art. 3.2); y el art. 1.2 de la Ley catalana 7/1997, de 18 de junio, de asociaciones, incurre en el mismo error que los Reales Decretos de Transferencia señalados, al exigir inexcusable y acumulativamente el requisito del domicilio de la asociación en Cataluña ("La presente Ley es de aplicación a las asociaciones que tienen el domicilio y desarrollan sus actividades principalmente en Cataluña...”).

Desde luego, el criterio del domicilio sería el más lógico y adecuado, además de ser el tradicionalmente utilizado para las personas jurídicas. Si en el apartado anterior llegábamos a la conclusión de que "funciones" ha de interpretarse como "actos de gestión o administración", y estos actos manifiestan la presencia del centro rector efectivo de la asociación -habida cuenta de que la realización de aquellos se encuentra encomendada a los correspondientes órganos rectores de la entidad-, la exigencia del domicilio resulta evidente siempre -claro está- que se la acompañe, a su vez, del requerimiento de que dicho domicilio sea fiel expresión del lugar donde la asociación está organizada jurídicamente y desde la que actúa ${ }^{23}$. Pero en cualquier caso, como hemos visto, éste no es el criterio que ha elegido el bloque de la constitucionalidad para las asociaciones.

En nuestra opinión, el canon debe extraerse de la valoración conjunta de los más diversos criterios, empezando por lo que expresen los propios estatutos de la asociación y continuando, en caso de conflicto, con otros elementos

\footnotetext{
22 Vid. Pedro De Pablo Contreras, «Artículo 44. XIII...», en Comentarios..., cit., p. 401.

${ }^{23}$ En el mismo sentido, Josep FERrER RIBA, «Fundaciones...», en Comentarios..., cit., p. 144, y Pedro De Pablo Contreras, «Artículo 44. XIII...», en Comentarios..., cit., p. 401.
} 
de juicio. Para evitar fraudes, las normas de desarrollo podrían imponer a las asociaciones determinadas cargas destinadas a justificar el desarrollo principal de sus funciones en Andalucía (presentación de proyectos y memoria de actividades cada cierto tiempo, etc.). En cualquier caso, como ha dicho la doctrina, la adopción de los actos de gestión como elemento definitorio de las "funciones" desempeñadas por la asociación atenúa los problemas de apreciación en cada caso concreto. Sería admisible, por ejemplo, una asociación andaluza que tuviera algunas delegaciones o locales abiertos o desempeñase cierta actividad contractual en otras Comunidades Autónomas. Y al contrario, no podría considerarse como andaluza una asociación cuyos actos de gestión realizados en el exterior del territorio andaluz fueran de tal envergadura que alguna de aquellas delegaciones hiciera de hecho las veces de domicilio social, o el volumen y entidad de las actuaciones contractuales exteriores fueran sensiblemente desproporcionadas con respecto a las llevadas a cabo en el interior de la Comunidad Autónoma de Andalucía.

En definitiva, ante la indeterminación del criterio utilizado por el legislador estatutario, no queda más remedio que ceñirse, en principio y a efectos prácticos, a la pauta adoptada por el legislador vasco: el ámbito de la asociación será el que determinen los estatutos asociativos correspondientes, sin perjuicio de que tanto el Estado como las Comunidades Autónomas desarrollen y establezcan los mecanismos normativos y organizativos necesarios para comprobar y favorecer, en el ámbito de sus competencias, que aquellas menciones estatutarias respondan a la realidad.

\section{DELIMITACIÓN NEGATIVA DE LA COMPETENCIA AU- TONÓMICA CON RESPECTO A OTROS TÍTULOS COMPE- TENCIALES DEL ESTADO: LA "NO EXCLUSIVIDAD" DE LA COMPETENCIA ANDALUZA SOBRE ASOCIACIONES}

Hemos de tener en cuenta que en el origen y posterior desarrollo del funcionamiento y actividades de una asociación existe el ejercicio de un derecho fundamental reconocido y rodeado de garantías en el art. 22 CE. Por esta razón, también al legislador autonómico afecta la reserva de Ley establecida en el art. 53.1 CE: "Los derechos y libertades reconocidos en el Capítulo segundo del presente Título vinculan a todos los poderes públicos. Sólo por ley, que en todo caso deberá respetar su contenido esencial, podrá regularse el ejercicio de tales derechos y libertades..."

Por otra parte, la dicción literal del Estatuto de Autonomía de Andalucía se refiere a la competencia de la Comunidad Autónoma sobre asociaciones 
con el adjetivo de "exclusiva". Sin embargo, quizá lo más adecuado sea calificarla como "plena", ya que, si bien las competencias andaluzas no se reducen a la función ejecutiva -a diferencia de la mayoría de las Comunidades Autónomas-, sino que incluye también la reglamentaria y la legislativa (art. $41.2 \mathrm{del}$ Estatuto), el Estado retiene importantes competencias en materia de asociaciones que, desde este punto de vista, constituyen un importante límite a la potestad normativa autonómica.

Por esta razón, aunque Andalucía tiene atribuidas notables competencias legislativas en la materia, éstas no son en puridad exclusivas sino, en cierta manera, compartidas con el Estado. Sería aplicable también aquí la teoría formulada y destinada por la doctrina a otros títulos de competencia, según la cual el título competencial de Andalucía sobre asociaciones sería un título autonómico residuat ${ }^{4}$. En efecto, a la materia asociativa, al encontrarse recogida tan sólo en los correspondientes Estatutos de Autonomía y no en los artículos 148 ni 149 CE, le sería aplicable la cláusula del apartado 3ํำ del art. 149 CE según el cual "las materias no atribuidas expresamente al Estado por esta Constitución podrán corresponder a las Comunidades Autónomas, en virtud de sus respectivos Estatutos". Esto quiere decir que las competencias estatutarias de Andalucía sobre asociaciones incluyen todos aquellos aspectos que no estén expresamente atribuidos al Estado en el art. 149.1 CE; y, al contrario, no podrán extenderse a todos aquellos segmentos de la materia asociativa que estén incluidos en otros títulos de competencia estatales. Y es que, efectivamente, existen en el art. 149.1 CE diversas competencias reconocidas al Estado en exclusiva y desde las cuales puede éste, en principio, legislar sobre asociaciones, con independencia de aquella otra capacidad normativa que ciertos Estatutos de Autonomía atribuyen -también en exclusiva- a algunas Comunidades Autónomas, entre ellas Andalucía.

Esta aparente contradicción entre las competencias estatales y autonómicas se resuelve desde la consideración, a que antes nos referíamos, de que no nos encontramos, pese el tenor literal del Estatuto, ante competencias exclu-

\footnotetext{
${ }^{24}$ Aunque refiriéndose a la materia "sanidad", emplea esta idea Manuel Rebollo Puig, Potestad sancionadora, alimentación y salud pública, INAP, Madrid, 1989, pp. 284 y 285; y, en el campo de la "defensa del consumidor", Juan Alfonso SANTAMARÍA PASTOR, «La regulación normativa de la distribución competencial», EC núm. 3 (1984), p. 166, para quien -desde la perspectiva del art. 149.3 CE- la eficacia del concepto "defensa del consumidor", en cuanto atributivo de competencias a las Comunidades Autónomas, es meramente residual: permitirá a éstas adoptar todas las actuaciones que no sean susceptibles de ser adscritas al Estado por pertenecer a alguna de las materias reservadas a éste por el art. $149 \mathrm{CE}$.
} 
sivas, sino compartidas entre el Estado y las Comunidad andaluza. Para delimitar el alcance real de la competencia legislativa de Andalucía sobre asociaciones hemos de atender, pues, a esos otros títulos de competencia estatales sobre materias en principio ajenas a la asociativa, pero sin embargo tan estrechamente ligadas a ella, que matizan aquella exclusividad convirtiéndola en compartida. Esos títulos de competencia estatales evocan de entrada las "condiciones básicas que garanticen la igualdad de todos los españoles en el ejercicio de los derechos y en el cumplimiento de los deberes constitucionales" (art. 149.1.1 $\mathrm{CE}$ ), así como la "legislación civil", los "registros" (ambos, art. 149.1.8 ${ }^{\circ} \mathrm{CE}$ ) o la "legislación procesal" (art. 149.1.6 ${ }^{\circ} \mathrm{CE}$ ). Pero antes hemos de referirnos también al límite que para la legislación autonómica supone el desarrollo del derecho fundamental de asociación por Ley orgánica del Estado $e x$ art. 81.1 CE.

\subsection{El desarrollo del derecho fundamental de asociación por el Estado ex art. 81.1 CE.}

Evidentemente, se trata del primer precepto que justifica la actividad normativa del legislador estatal en materia de asociaciones. El art. $22 \mathrm{CE}$ es el que reconoce con carácter general el derecho de asociación como derecho fundamental. La STC 173/1998 dice que se trata del "derecho genérico" de asociación y "parcialmente" regulado en este precepto. El art. 81.1 CE prevé que tal derecho sea desarrollado por Ley orgánica.

Sin embargo, la STC 173/1998 recuerda, reiterando la doctrina sentada en la STC 137/1986, de 6 de noviembre, que esta reserva de Ley orgánica no supone por sí sola y en cuanto tal, un título competencial a favor del Estado sobre la materia de asociaciones ${ }^{25}$.

${ }^{25} \mathrm{FJ} 7^{\circ}$. El TC llega a esta conclusión por varias razones: 1) En primer lugar, es necesario mantener una posición restrictiva en cuanto al uso de la técnica de la Ley orgánica como instrumento "excepcional" o "extraordinario" para evitar tanto las "petrificaciones" del Ordenamiento jurídico que podrían producirse en el caso de utilizar indiscriminadamente esta forma legislativa en amplios sectores de la reglamentación jurídica, como el peligro de que las Cortes corran el riesgo por esta vía de convertirse en una suerte de "constituyente permanente"; 2) En segundo lugar, porque el ámbito de la reserva de Ley orgánica no es coextenso al de las competencias atribuidas al Estado por la CE; 3) En tercer lugar, al fijarse el alcance de la reserva de Ley orgánica, debe cohonestarse ésta con el contenido del bloque de la constitucionalidad que distribuye las competencias entre el Estado y las Comunidades Autónomas. En la misma línea, vid. Enrique LuCAS MuRILlO DE LA CUEVA, Igualdad y autonomía..., cit., pp. 51 ss. 
Este planteamiento lleva al TC a varias conclusiones relevantes en la cuestión que nos ocupa. La primera es la enorme importancia de determinar el alcance material de la reserva de Ley orgánica. En este sentido, afirma el TC, la Ley orgánica tiene reservados sólo los aspectos esenciales para la definición del derecho, la previsión de su ámbito y la fijación de sus límites en relación con otras libertades constitucionalmente protegidas. La Ley orgánica debe limitarse, por tanto, y aquí llegamos al núcleo de la cuestión, a la regulación de los aspectos esenciales, al desarrollo directo del derecho fundamental considerado "en cuanto tal"; y dejar la regulación de la "materia" sobre la que se proyecta el derecho al legislador ordinario con competencias sectoriales en la misma, siendo este legislador ordinario el estatal o el autonómico, dependiendo de la distribución de competencias existente en esa concreta materia sectorial sobre la que se proyecta el derecho fundamental. A lo primero el TC lo llama "regulación del derecho de asociación" y a lo segundo "régimen jurídico de las asociaciones" $" 6$.

La doctrina ${ }^{27}$, por su parte, y teniendo ante sí las conclusiones formuladas por la STC 173/1998, ha cifrado los elementos que han de ser objeto de regulación por Ley orgánica en:

a) la titularidad del derecho;

b) las facultades elementales que integran su contenido, tanto en relación con los poderes públicos como en el seno de las relaciones entre particulares;

c) las garantías fundamentales para preservarlos frente a la injerencia de los poderes públicos;

d) los limites en relación con otros derechos y libertades constitucionalmente reconocidos.

\footnotetext{
${ }^{26}$ Sobre la base de estos planteamientos, el FJ $13^{\circ}$ de la STC 173/1998 declara inconstitucionales los preceptos de la Ley vasca de asociaciones que exigían "que la organización y funcionamiento de las asociaciones será democrática" (art. 2.4) y "[la constitución] se llevará a cabo con respeto al pluralismo y a los principios democráticos". Se estima que unas previsiones con este alcance suponen desarrollo del derecho fundamental de asociación y que, por tanto, es materia de Ley orgánica, la cual sólo puede ser emanada por el legislador estatal, estándole la misma vedada por completo al legislador autonómico.

27 Vid. Enrique LuCAS Murillo de la Cueva, Igualdad y autonomía..., cit., pp. 46 y ss.
} 
Finalmente, a este esquema responde la regulación actual de la LORDA, que se configura en consecuencia como un ejemplo de "Ley parcialmente orgánica” 28 , y cuyos preceptos con rango de Ley orgánica cubren las siguientes materias: el objeto y el ámbito de aplicación de la Ley (art. 1); las facultades esenciales que integran el contenido del derecho de asociación y los principios que lo informan (artículos 2, 19, 21, 23.1, 24); algunos extremos relativos a la titularidad y la capacidad de constituir asociaciones (artículos 2.1 y 3 ); una serie de garantías fundamentales frente a la eventual injerencia de los poderes públicos (artículos 4.2, 10.1, apartados 3 y 4 del art. 30 y artículos 37 y 38 ); y una serie de limitaciones frente a otras libertades y derechos constitucionales (art. 2.5 - exigencia de funcionamiento interno democrático-, apartados 5 y 6 del art. 4 -inasistencia de los poderes públicos respecto de las asociaciones que promuevan la discriminación o el terrorismo-, art. $29.1-\mathrm{pu}-$ blicidad del Registro de Asociaciones- ). Todos estos preceptos se entienden directamente aplicables en todo el territorio nacional, independientemente del sistema de reparto de competencias entre el Estado y las Comunidades Autónomas, pues constituyen el desarrollo directo del derecho fundamental de asociación consagrado en el art. 22 CE.

\subsection{Las competencias del Estado sobre las "condiciones básicas que garanti- cen la igualdad de todos los españoles en el ejercicio" del derecho de asocia- ción (art. 149.1.1ำ $\mathrm{CE}$ )}

Por seguir con la terminología adoptada en la STC 173/1998, que distingue entre "regulación del derecho de asociación" y "régimen jurídico de asociaciones", nos encontramos ahora ante el primero de los preceptos capaces de ofrecer al Estado una cobertura suficiente para abordar ciertos aspectos de esto último, es decir, del "régimen jurídico de las asociaciones", aplicable directamente incluso en el territorio de las Comunidades Autónomas con competencia exclusiva en materia de asociaciones ${ }^{29}$.

\footnotetext{
${ }^{28}$ Para Germán Fernández FarReres, Derecho de Asociación..., cit., p. 491, la LORDA se ajusta adecuadamente a la doctrina de la relación Ley ordinaria-Ley orgánica, al menos en términos estrictamente formales.

${ }^{29}$ Así lo entendió también la Comisión Mixta autora del RD 304/1985, de 6 de febrero, de Traspaso de funciones y servicios del Estado en materia de Asociaciones a la Comunidad Autónoma de Andalucía, que invoca el art. 149.1.1ํㅡㄹ $\mathrm{CE}$ [Anexo I, A)]. Por lo demás, este título competencial fue reiteradamente traído por la doctrina para la elaboración de una nueva normativa sobre fundaciones conforme a los esquemas inaugurados por el art. $34 \mathrm{CE}$. Con rasgos similares al problema del derecho de asociación, el derecho de fundación no es objeto de un apoderamiento constitucional expreso a favor del Estado, y sí de algunas Comunidades Autónomas por la
} 
Establece este art. 149.1.1ํ CE que el Estado tiene competencia exclusiva sobre "la regulación de las condiciones básicas que garanticen la igualdad de todos los españoles en el ejercicio de los derechos y en el cumplimiento de los deberes constitucionales". Es evidente que el derecho de asociación forma parte de esos derechos constitucionales cuyas condiciones básicas deben estar reguladas uniformemente en orden a salvaguardar la igualdad de todos los españoles en su ejercicio.

Por tanto, se trata de un título competencial que permite al Estado legislar sobre el derecho de asociación ${ }^{30}$. Pero desde este momento conviene precisar que tal afirmación debe matizarse en el sentido de que el Estado, al legislar sobre la base de este título, cuenta con unos límites bien claros, basados en la propia literalidad del precepto:

1) En primer lugar, se trata de legislar sobre las "bases", sobre las "condiciones básicas", no sobre el completo régimen jurídico ${ }^{31}$;

vía estatutaria. Se decía que el Estado es competente para dictar una norma general en materia de fundaciones con título en el art. 149.1.1 ${ }^{\circ} \mathrm{CE}$, entre otros, pues se entiende que el derecho de fundación ubicado en el art. $34 \mathrm{CE}$ es uno de esos "derechos constitucionales" a los que se refiere el 149.1.1 ${ }^{\circ}$ CE. Esta postura se vio finalmente respaldada por la actuación del legislador en 1994, cuando se promulga la Ley 30/1994, de 24 de noviembre, de Fundaciones y de Incentivos Fiscales a la Participación Privada en Actividades de Interés General (BOE de 25 de noviembre de 1994, núm. 282). Su DF $1^{1}$ establecía que eran de directa aplicación en todo el Estado al amparo del art. 149.1.1 $\mathrm{CE}$ los preceptos de la Ley que se referían al concepto de fundación, fines y beneficiarios de la actividad fundacional, todo lo relativo al momento y forma de adquisición de la personalidad jurídica por parte del ente fundacional, capacidad genérica para fundar, modalidades genéricas y forma de constitución, previsión general del Patronato como órgano de gobierno y, finalmente, las causas de extinción. La DF $1^{\underline{a}}$ de la nueva Ley 50/2002, de 26 de diciembre, de Fundaciones (BOE de 27 de diciembre, núm. 310) refiere casi a los mismos aspectos el título competencial contenido en el art. 149.1.1 $\mathrm{CE}$, a excepción de la capacidad para fundar (art. 8), que entiende alojado en el art. 149.1.8 ${ }^{\circ}$ CE ("legislación civil"). Añade, además, las finalidades a que se ciñen las facultades del Protectorado (art. 34.1). Vid. Eduardo GARCía DE ENTERRíA, «Constitución, fundaciones y sociedad civil», RAP núm. 122 (1990), pp. 252 y 253.

30 Vid. Germán Fernández Farreres, Asociaciones..., cit., pp.137-143; Diego MarTín MERChán, «El derecho de asociación y las Comunidades Autónomas», DA núm 195 (1982), p. 218.

${ }^{31}$ No conviene, sin embargo, confundir esto con el esquema bases-desarrollo, mediante el que se articulan las relaciones entre legislación básica estatal emanada al amparo de los demás apartados del 149.1 CE y legislación autonómica de desarrollo de dicha legislación básica estatal. La razón es que este 149.1.1ำ $\mathrm{CE}$ se refiere a la regulación directa y exclusiva de los elementos y aspectos del derecho que garantizan que las posiciones jurídicas fundamentales de todos los españoles son las mismas con respecto al derecho en cuestión. Es decir, que no se ofrece a las Comunidades Autónomas un espacio para que determinen su propia orientación política a partir de las condiciones básicas fijadas por el Estado sobre la materia de que se trate como algo susceptible 
2) En segundo lugar, dicha potestad normativa se halla delimitada por un fin, cual es el de asegurar la igualdad en el ejercicio del derecho, y sólo en tal medida está justificada la intervención legislativa del Estado.

Dicha regulación básica, por supuesto, debe respetar, además, el contenido esencial del derecho de asociación tal y como viene definido en el art. 22 $\mathrm{CE}$, por imperativo del art. 53.1 $\mathrm{CE}^{32}$.

Ante la inexistencia de Ley estatal post-constitucional, la tarea de delimitación de la STC 173/1998 se vio enormemente dificultada, llegando a decir, con un alto grado de abstracción ${ }^{33}$, que a falta de dicha normativa estatal, las Comunidades Autónomas competentes en materia de asociaciones podrán legislar siempre que se respeten los principios que inmediatamente se derivan de la CE. Pese a estas dificultades, la STC 173/1998 deja claro, siempre desde la ardua posición de no contar con la existencia de una norma estatal concreta, que estamos ante un título competencial con contenido propio, no residual, que habilita al Estado para regular el "contenido primario del derecho, las posiciones jurídicas fundamentales (facultades elementales, límites esenciales, deberes fundamentales, prestaciones básicas, ciertas premisas o presupuestos previos...)", aunque subraya que "no el diseño completo y acabado de su régimen jurídico". Sobre esta base, el TC precisa que se pueden considerar

de desarrollo dentro de unos parámetros predeterminados. Aquí el campo que le queda al legislador autonómico es más limitado porque cuando la materia versa sobre derechos fundamentales abundan las situaciones en que la única vía para garantizar la igualdad en estas posiciones fundamentales es darles el mismo contenido para todo el Estado. Vid., en este sentido, Enrique LuCAS Murillo DE LA CUeva, Igualdad y autonomía..., cit., pp. 77 y 78.

32 Vid. Diego Martín Merchán, «El derecho de asociación...», cit., p. 225; Pedro De Pablo ConTRERAS, «Tres competencias de Derecho privado en el artículo 44 del Amejoramiento: asociaciones, fundaciones y centros de contratación de mercaderías y valores», RJN núm. 3 (1987), pp. 36 y 37 .

${ }^{33}$ Imprecisión en los términos que se ha puesto de relieve en algunos comentarios a esta Sentencia; vid. Sofía DE SALAS Murillo, "Consideraciones en torno a las disposiciones generales de la nueva Ley catalana de asociaciones (Ley 7/1997, de 18 de junio, de asociaciones)», $D P y C$ núm. 11 (1997), p. 444, y Amelia Pascual Medrano, «La Sentencia del Tribunal Constitucional 173/1998 sobre la Ley Vasca de Asociaciones», Estudios, Repertorio de Jurisprudencia TC, Aranzadi, Vol. I, 1999, p. 1864. Germán Fernández Farreres, Derecho de Asociación..., cit., pp. 494 y 495, se hace eco de los formidables obstáculos existentes para distinguir lo que es materia reservada a Ley orgánica de lo que es objeto de regulación ordinaria $e x$ art. 149.1.1 ${ }^{\circ} \mathrm{CE}$ por la enorme similitud funcional de ambos tipos de preceptos, dificultad que aumenta de grado cuando el juicio de constitucionalidad sobre una Ley autonómica se hace sin contar con previa Ley orgánica ni Ley ordinaria básica ex art. 149.1.1ํㅡ. EEsto es cabalmente lo que le ocurre a la STC 173/1998. 
“condiciones básicas" a los efectos del 149.1.1ํㅡ CE tanto la definición del concepto legal de asociación, como aquellos aspectos concretos que se refieren más a su dimensión externa, como el nacimiento de la personalidad ${ }^{34}$, la capacidad jurídica y de obrar, el régimen de responsabilidades y las causas y efectos de la disolución. Para el TC estos elementos resultan imprescindibles o necesarios para asegurar la igualdad de todos los españoles en el ejercicio del derecho de asociación y, en cuanto tales, requieren un tratamiento uniforme ${ }^{35}$. Una de las consecuencias, derivadas de lo dicho, era que cuando el Estado dictara en un futuro estas condiciones básicas al amparo del art. 149.1.1ํㅡㄹ $\mathrm{CE}$, al establecerlas, éstas entraran en colisión con preceptos autonómicos en vigor, éstos quedarían automáticamente desplazados por aquéllas, ya que constituyen un núcleo de regulación uniforme del que ineludiblemente debe partir la regulación de los distintos tipos de asociaciones ${ }^{36}$. Y esto es, precisamente, lo

\footnotetext{
${ }^{34}$ En este punto el TC realiza una interesante incursión en el tan debatido problema del momento de la adquisición de personalidad jurídica por parte del ente asociativo. Piensa que pertenece al Estado $e x$ art. 149.1.1 ${ }^{\circ}$ CE la competencia para determinar los efectos que pueden atribuirse a la inscripción en el registro de asociaciones en relación con la adquisición o no de personalidad jurídica. Para el TC esta cuestión constituye una de las condiciones básicas del nacimiento de la personalidad jurídica que resulta imprescindible para garantizar el ejercicio del derecho en condiciones de igualdad. El art. $35 \mathrm{CC}$ se limita a decir que las asociaciones adquieren personalidad jurídica cuando hayan quedado válidamente constituidas. Esta remisión del CC a una previsión legal que en el ordenamiento del Estado era hasta la promulgación de la LORDA inexistente, es la que lleva al TC a mantener que, en tanto las Cortes no se pronuncien, nada cabe objetar al legislador autonómico cuando da solución a este concreto extremo, como así ha hecho la Ley Vasca de Asociaciones en el art. 9 y cuya validez, por tanto, salva la STC 173/1998 sobre la base de estas consideraciones (vid. FJ 14.f). Con posterioridad a este pronunciamiento jurisdiccional, el art. 5 LORDA ha pasado a regular actualmente este extremo -al amparo, precisamente, del 149.1.1 ${ }^{\circ} \mathrm{CE}$-, cosa que supone el desplazamiento de la normativa autonómica: la asociación, cualquiera que sea su ámbito de actuación (estatal o autonómico), adquiere personalidad jurídica con la formalización del acuerdo de constitución en acta, que puede ser tanto en documento público como privado. Sobre el problema del modo y el momento de la adquisición de personalidad jurídica por las asociaciones, puede consultarse la completa síntesis de Sofía DE Salas MuRillo, Las asociaciones sin ánimo de lucro en el Derecho español, Centro de Estudios Registrales, Madrid, 1999, pp. 558-579.

${ }^{35} \mathrm{FJ} 9^{\circ}$. Obsérvese que las condiciones consideradas básicas a los efectos de ser incluidas en el ámbito del art. 149.1.1 ${ }^{\circ} \mathrm{CE}$ coinciden sustancialmente con los elementos que enumeraba la Ley de Fundaciones de 1994 entre los que encuentran cobertura en este art. de la CE (DF $1^{\underline{a}}$ de la Ley 30/1994, de 24 de noviembre, de Fundaciones e Incentivos Fiscales a la Participación Privada en Actividades de Interés General). También la DF $1^{\underline{a}}$ de la actual Ley 50/2002, de Fundaciones.

${ }^{36}$ STC 173/1998, F.J. 9º. Para Amelia Pascual Medrano, «La Sentencia...», cit., pp. 1860-1862, salvar de esta forma la regulación autonómica introduce un alto grado de inseguridad jurídica, al quedar ésta sometida a condición.
} 
que ha sucedido con la aprobación de la LORDA en 2002 respecto a diversos preceptos de las Leyes vasca y catalana de asociaciones.

Por su parte, la doctrina que con más detenimiento se ha ocupado de estas cuestiones, y siguiendo en todo momento lo dicho por la STC 173/1998, piensa que la Ley ordinaria estatal dictada al amparo del 149.1.1 ${ }^{\circ} \mathrm{CE}$, en general, puede regular el contenido primario, las posiciones jurídicas fundamentales y las facultades básicas del derecho, pero en tanto sea imprescindible para garantizar la igualdad en su ejercicio. Esto, aplicado al derecho de asociación, significa que el Estado goza de libertad para apreciar en cada momento los elementos que se consideren comúnmente "requisitos mínimos indispensables" para ejercitar el derecho de asociación, pero bajo el condicionamiento de dos circunstancias concurrentes: que se constate la necesidad de que su régimen jurídico sea uniforme para garantizar la igualdad, y que la uniformidad de la regulación se limite a lo imprescindible para lograr la igualdad en el ejercicio del derecho ${ }^{37}$.

Pues bien, lo que la LORDA finalmente ha optado por regular como condiciones básicas al amparo del art. 149.1.1ํㅡㄹ $\mathrm{CE}$ es:

a) La definición del concepto legal de asociación y todo lo relativo a la constitución y adquisición de personalidad jurídica: artículos 5 y 6 , y DT $1 \stackrel{\text { a }}{\text {. }}$.

b) La capacidad jurídica y de obrar y organización mínima: artículos 2.6, $3 . \mathrm{g}), 7,8,9,11,13.2$ y 22.

c) El régimen de responsabilidad: apartados 2, 3 y 4 del art. 10, artículos $15,25.2,26,27,28$, apartados 1,2 y 5 del art. 30 , y DA 4 a . En este apartado incluimos los preceptos dedicados a los registros de asociaciones, habida cuenta de la conexión que establece la Ley entre éstos y el sistema de responsabilidad.

d) Las causas y los efectos de la disolución: artículos 17 y 18.4 .

e) Actividad administrativa de fomento - formulada en términos muy genéricos- para las asociaciones de interés general: apartados 1 y 4 del art. 4 .

${ }^{37}$ Vid. Enrique Lucas Murillo de LA Cueva, Igualdad y autonomía..., cit., pp. 140-142. 


\subsection{Las competencias del Estado sobre la "legislación civil" (art. 149.1.8 $\mathrm{CE}$ ): su casi total irrelevancia final}

Otro de los títulos competenciales atribuido al Estado por el art. 149.1 CE y que podría entenderse vinculado a la materia asociativa, es la regla $8^{\mathrm{a}}$, que atribuye al legislador estatal la "competencia exclusiva" sobre "legislación civil, sin perjuicio de la conservación, modificación y desarrollo por las Comunidades Autónomas de los derechos civiles, forales o especiales". Además, en cualquier caso, la $\mathrm{CE}$ reserva al Estado en el contexto de este mismo precepto las reglas relativas a la aplicación y eficacia de las normas jurídicas, la ordenación de los registros e instrumentos públicos y las bases de las obligaciones contractuales.

Sobre esta cuestión pueden detectarse dos interpretaciones doctrinales contrapuestas: una concepción amplia de la noción "legislación civil", que implicaría considerar incluido en dicho título competencial la materia asociaciones; y una concepción que sitúa esta materia fuera de la órbita del Derecho privado debido al influjo jurídico-público que —según estos autores- la Constitución ha patrocinado sobre la misma.

Entre los argumentos manejados por la primera tendencia, se sitúan algunos autores para los que la materia asociativa se entendería comprendida en el concepto más amplio de "legislación civil" en cuanto que el ente asociativo se ha concebido tradicionalmente como una persona jurídico-privada regulada por el Derecho civil.

Esta doctrina ha hecho un esfuerzo por aclarar a qué se refiere el art. 149.1.8 ${ }^{\circ}$ CE cuando habla de "legislación civil". Entre las reflexiones que se han formulado, destaca la idea del "carácter reversible" de ciertas instituciones jurídico-civiles reguladas, en principio, por la "legislación civil”. Este concepto significaría que determinadas figuras jurídico-privadas son constitucionalmente susceptibles de una interpretación en clave de Derecho público. La consecuencia es que las Comunidades Autónomas competentes en la materia de que se trate pueden regular, por ejemplo, la posición jurídica de las entidades públicas sin que, al hacerlo, quede excluida la facultad de incidir en la de los particulares afectados por la actuación de aquéllas; e incluye también la posibilidad de regular esta última aunque siempre en una "dimensión vertical" y no "horizontal", esto es, sin trascendencia "inter privatos". Así, las Comunidades Autónomas sin competencias sobre Derecho civil podrían regular cuestiones que supongan menoscabo o desplazamiento de las situaciones ordinarias de Derecho privado, siempre que de tal regulación surjan tan sólo 
pretensiones frente a los poderes públicos, y no frente a otros particulares. Para esta doctrina esto último sería el "núcleo irreductible" de lo que habría de entenderse por "legislación civil" reservada en exclusiva al Estado ex art. 149.1.8 CE $^{38}$. Por eso, comentando la STC 173/1998 sobre la Ley Vasca de Asociaciones, se ha sostenido que "no parece que pueda ofrecer ninguna duda la afirmación de que las asociaciones a que se refiere el art. 10.3 ECPV son personas jurídicas privadas (...), como tampoco que buena parte de su régimen jurídico pertenece al ámbito propio del Derecho privado (...). Son, en efecto, cuestiones clave a dilucidar por el legislador las de adquisición por el ente de la personalidad jurídica, su capacidad de obrar en las relaciones con otros particulares, su responsabilidad frente a terceros, los derechos y deberes de los asociados...; cuestiones, todas ellas, que comportan pretensiones de un particular frente a otro u otros y que, por ello, son de Derecho privado, correspondiendo su conocimiento, en caso de litigio, a la jurisdicción civil”39.

Se ha precisado, incluso, al hilo de los argumentos esgrimidos por la defensa de la Comunidad Autónoma del País Vasco en el asunto que resuelve la STC 173/1998, que la materia "asociaciones" no es una materia "más específica" que la de "legislación civil" en el sentido de justificarse una competencia autonómica sobre aquélla por encima de ésta, que sí correspondería al Estado, sino que la materia "asociaciones", de alguna manera, se encuentra alojada, al menos en parte, en la "legislación civil" 40 .

\footnotetext{
38 Vid. Pedro De PABLo Contreras, «La "legislación civil” y la competencia autonómica en materia de asociaciones (A propósito de la STC 173/1998, de 23 de julio)», Estudios, Repertorio de Jurisprudencia TC, Aranzadi, Vol. I, 1999, pp. 1841 y 1842. Extrae tal línea de pensamiento de las SSTC 37/1987 (en la que el TC no pone obstáculos a que la Ley andaluza de reforma agraria imponga limitaciones del dominio sin relevancia "inter privatos") y 71/1982 (en la que el TC pone reparos a la intervención de normas autonómicas en el Derecho de la contratación y en el régimen de la responsabilidad contractual al amparo de la competencia en materia de protección de los consumidores). Por su parte, Luis Díez-PICAZO y PONCE DE LEÓN, «Las competencias del Estado y de las Comunidades Autónomas en materia de Derecho civil», en Competencias en materia civil de las Comunidades Autónomas, coord. por Bernardo Moreno Quesada, Tecnos, Madrid, 1989, pp. 18 y 19, al enumerar las materias que en su opinión integrarían la "legislación civil" del 149.1.8ํㅡㄹ $\mathrm{CE}$, no se refiere en ningún momento a las asociaciones, pero alude indirectamente a este "carácter reversible" jurídico-público de ciertas figuras jurídico-privadas, sobre todo del derecho de propiedad (las llamadas "propiedades especiales”).
}

39 Pedro De Pablo Contreras, «La "legislación civil”... », cit., p. 1832.

${ }^{40}$ En este sentido, vid. también Pedro De Pablo Contreras, «La "legislación civil”...», cit., pp. 1835-1839: critica la incoherencia del TC en este punto en relación a pronunciamientos propios anteriores, pues en la STC 173/1998 el Tribunal reconoce de alguna manera la pretendida especialidad de la materia "asociaciones" sobre la de "legislación civil" para salvar la constitucionalidad de la normativa autonómica. 
Definiciones como éstas, que se caracterizan por su amplitud y por la aproximación conceptual que realizan entre la "legislación civil" del 149.1.8 CE y el Derecho civil como disciplina académica o científica hasta casi identificarlas entre sí, son las que están en la base de las posiciones doctrinales que defienden la inclusión de la materia asociativa entre las competencias estatales al amparo del art. 149.1.8 $\mathrm{CE}$, sobre todo al estimarse que la legislación civil se extendería a la "ordenación jurídica de la persona" y la "capacidad" 41 . Así, para MARÍN LÓPEZ es precisamente en este precepto donde se encuentra el título competencial exclusivo del Estado de mayor intensidad para intervenir legislativamente en materia de asociaciones ${ }^{42}$, aunque precisa que no en exclusiva sobre "todo" el régimen jurídico de las asociaciones, sino sólo sobre aquellos aspectos de dicho régimen que se refieran al concepto de asociación, los elementos constitutivos del contrato plurilateral asociativo que está en la base del ente asociativo (consentimiento, objeto, causa, forma) ${ }^{43}$, los requisitos de capacidad jurídica necesarios para constituir una asociación o adherirse a ella, la adquisición de personalidad jurídica por el ente asociativo, la dis-

\footnotetext{
${ }^{41}$ Así, el Dictamen nํㅜ 144 del Consejo Consultivo de la Generalitat de Catalunya, de 15 de marzo de 1988, en relación con la adecuación a la Constitución y al Estatuto de Autonomía del Dictamen de la Comisión de Política Cultural sobre el Proyecto de Ley del Deporte, Dictámenes del Consejo Consultivo de la Generalidad de Cataluña, 1988, Vol. II, sostuvo que las competencias de la Generalidad respecto de la materia asociativa en el ámbito del deporte han de ser acotadas en atención no sólo a los artículos 22, 81 y 149.1.1ํㅡㄹ $\mathrm{CE}$, sino también al art. 149.1.8o en cuanto que reserva al Estado la competencia exclusiva en materia de "legislación civil" (p. 117).

42 Vid. «Artículo 20», en Comentarios a la Ley General de Defensa de los Consumidores y Usuarios, coord. por RODRIGO BERCOVITZ y JAVIER SALAS, Civitas, Madrid, 1992, pp. 512-516. Refuerza este argumento recurriendo a la atribución que realiza la STC 17/1990 de competencias autonómicas sobre las entidades de gestión de aguas de Canarias, ya que la Ley las configuraba como Corporaciones de Derecho Público, y no "comunidades" de Derecho privado, en las que sí entraría en juego, precisa el TC, la "legislación civil" del art. 149.1.8 ${ }^{\circ} \mathrm{CE}$. Por otra parte, critica que la mayoría de los autores que se han dedicado con más profusión al problema de la distribución de competencias en materia de asociaciones no acudan a este precepto, limitándose básicamente a los artículos 22, 81 y 149.1.1ํㅡㄹ CE (MARTín Merchán, Fernández Farreres). Tampoco analiza la incidencia del título competencial recogido en el 149.1.8 ${ }^{\circ}$ CE sobre la materia asociativa, en la que tienen especial protagonismo las asociaciones y federaciones deportivas, José A. RAzQUíN LIZARRAGA, «Deporte y Comunidades Autónomas. Aspectos competenciales», REALA núm. 249 (1991), que limita sus observaciones a los artículos 22 y 149.1.1. CE.
}

${ }^{43}$ Entendemos, sin embargo, con el TC, que el acto constitutivo de una asociación no es equiparable al contrato de sociedad, sino que es algo más amplio, el ejercicio de un derecho de libertad (a este acto, por tanto, no podría aplicársele la doctrina civil de la causa del contrato, por ejemplo) (Vid. FJ $9^{\circ}$ de la STC 5/1996). Sobre el debate jurídico acerca de la naturaleza del acto constitutivo de las asociaciones y sus consecuencias prácticas, vid. Sofía DE SALAS Murillo, Las asociaciones sin ánimo de lucro..., cit., pp. 426-470. 


\section{ciplina del patrimonio asociativo, las causas de extinción de la asociación o el destino del patrimonio remanente ${ }^{44}$.}

Frente a concepciones tan amplias, hay otras corrientes doctrinales que son más restrictivas con respecto al campo de acción que puede desplegar el art. 149.1.8 ${ }^{\circ} \mathrm{CE}$ en la materia, sobre todo en lo que respecta a las Comunida-

44 Vid. Juan José MARÍN LÓPEZ, «Artículo 20», en Comentarios..., cit. p. 513. En este mismo sentido, vid. también Pedro De Pablo Contreras, «Artículo 44. XIII...», en Comentarios..., cit., p. 403: "Es claro sin embargo, que la genérica atribución de personalidad jurídica a las asociaciones (art. 35 del Código Civil), así como la determinación de la capacidad de obrar de las mismas en cuanto que personas jurídicas (art. 38 del Código Civil), sí que son cuestiones a encuadrar dentro del concepto de legislación civil del art. 149.1.8 ${ }^{\mathrm{a}}$ de la norma fundamental”. Por lo que se refiere a las asociaciones deportivas, la Ley estatal del deporte de 1990 declara en su DA $1^{\underline{a}}$ que el art. 15, precepto que define el asociacionismo deportivo, es aplicable a todo el territorio del Estado, superponiéndose por tanto a las posibles regulaciones de las Comunidades Autónomas con competencias en la materia deportiva. Pero no dice la Ley, ni refiriéndose a este precepto ni a ningún otro, en qué título competencial apoya tal previsión, aunque sería lógico pensar que lo hace sobre la base de la "legislación civil" del 149.1.8 CE, y no, en contra de lo sostenido por Juan José MARín López ( «Artículo 20», en Comentarios..., cit., pp. 508-510), sobre la base de una pretendida "dimensión esencial o sustancial" que comportaría la exigencia de norma del Estado. Pensamos que el peso jurídico de tal argumento es insuficiente si no se acude a las previsiones contenidas en los artículos 149.1.1o ó 149.1.8 $\mathrm{CE}$. Otro argumento llamado a jugar un importante papel a favor de las tesis amplias, es el relativo al derecho de fundación. Al igual que sucedía respecto de la competencia definida en el art. 149.1.1ํ $\mathrm{CE}$ y que ya comentamos, el precepto recogido en el 149.1.8 $\mathrm{CE}$ ha sido invocado también por la doctrina en orden a justificar la intervención estatal en el establecimiento del régimen jurídico del derecho de fundación, pues es evidente la configuración de las fundaciones como personas jurídico-civiles, que caerían, por tanto, bajo el concepto de "legislación civil". Es la línea propugnada por Eduardo GARCÍA DE ENTERRÍA, «Constitución...», cit., pp. 252 y 253. En este sentido, véase también Juan José MARÍN LÓPEZ, «Artículo 20», en Comentarios..., cit., pp. 509 y 510. En efecto, sostiene este último autor que, a pesar de no estar esta materia expresamente recogida en el art. 149.1 CE y haberla asumido ciertas Comunidades Autónomas, algunas de las cuales incluso han dictado sus propias leyes de fundaciones (situaciones comunes todas ellas con el derecho de asociación en la actualidad), el Estado retiene competencias en materia de fundaciones vía 149.1.8 ${ }^{\circ} \mathrm{CE}$ (Derecho civil). En concreto, para este autor, dichas facultades legislativas estatales se extenderían a: las condiciones legales para que un ente se considere fundación, precisión del concepto "fin benéfico", dotación, destino de los bienes en caso de disolución, etc. A salvo esto para las Comunidades Autónomas con Derecho civil propio que incluya la materia fundaciones, entre las que no hay duda que se encuentra Navarra. El resto de Comunidades Autónomas sin Derecho civil propio sólo podrían legislar en cuanto a la intervención administrativa de las fundaciones (fomento, protectorado, tutela...). Por su parte, Josep FERRER RIBA, «Fundaciones...», en Comentarios..., cit., p. 150, pone de relieve la dificultad intrínseca de la cuestión, pues piensa que en las fundaciones se dan las notas características de las organizaciones sociales, una de tantas categorías nuevas en las que se resuelve la llamada crisis de la distinción Derecho público-Derecho privado, pues en su régimen jurídico se hallan indisolublemente implicados aspectos de uno y otro sector del Ordenamiento. En 
des Autónomas que hayan asumido competencias exclusivas sobre asociaciones por vía estatutaria, las cuales no encontrarían prácticamente ningún límite en este precepto constitucional. Los argumentos utilizados son de dos tipos:

- El primero: el TC rechaza una definición de "legislación civil" en el sentido doctrinal de disciplina académica.

- El segundo: las asociaciones, pese a ser personas jurídico-privadas, persiguen, sin embargo, un interés general que implica una más intensa intervención de la Administración, y por lo mismo del Derecho público, en su desenvolvimiento ${ }^{45}$.

En cualquier caso, podemos decir que esta última corriente es la que se ha impuesto en la jurisprudencia constitucional, primero, y en la obra del legislador, después.

En efecto, por lo que se refiere a la jurisprudencia constitucional, la STC 173/1998 no acude al art. 149.1. $8^{\circ}$ CE para analizar las competencias estatales en materia de asociaciones ${ }^{46}$, actitud que ha criticado la doctrina favorable a

cualquier caso, la legislación posterior se ha hecho eco de las reflexiones doctrinales aludidas, de manera que la DF 1 $\stackrel{a}{ }$, apartado 2, de la Ley 30/1994, de Fundaciones e Incentivos Fiscales a la Participación Privada en Actividades de Interés General, estableció que se dictaban al amparo del 149.1.8 ${ }^{\circ}$ CE y eran, por tanto, de aplicación general normas relativas al domicilio y a las fundaciones extranjeras que ejercitaran actividades en España. Del mismo modo, eran de aplicación directa en todo el territorio pero supletoria en las Comunidades Autónomas con competencia en Derecho civil, foral o especial, las previsiones referentes a: ciertos aspectos sobre la capacidad para fundar, la fundación por acto "mortis causa", el régimen de la escritura de constitución, el contenido mínimo de los estatutos de la fundación, previsiones genéricas sobre la dotación, el régimen de la fundación en formación, las atribuciones generales del patronato como órgano de gobierno y gestión de la fundación, el régimen de la responsabilidad civil de los patronos ante la propia Fundación, los supuestos de cese de los patronos, la composición del patrimonio de la fundación, el carácter de la aceptación de herencias por parte de la fundación, algunos extremos de la modificación de estatutos, el supuesto de fusión por imposibilidad del cumplimiento de los fines, formas de extinción, previsión genérica de la figura del protectorado, y, finalmente, los supuestos de intervención de la fundación por parte del protectorado. De igual forma, la DF $1^{\underline{a}}$ de la nueva Ley 50/2002, de Fundaciones, remite los mismos aspectos a idéntico título competencial del Estado.

45 Vid. Enrique LuCAS Murillo De la Cueva, Igualdad y autonomía ..., cit., p. 144.

${ }^{46}$ El Tribunal, efectivamente, enuncia en el FJ $6^{\circ}$ los preceptos constitucionales que le van a servir de base para desempeñar el análisis de la cuestión debatida. Cita los artículos 81.1, 139.1, 149.1.1 ${ }^{\circ}$ y 149.1.6 ${ }^{\circ} \mathrm{CE}$, ignorando por completo el 149.1.8ํㅡ $\mathrm{CE}$ en lo tocante a la "legislación civil". Sí se refiere en su FJ $14^{\circ} d$ ) a este art., aunque sólo en cuanto a la "ordenación de los instru- 
la tesis amplia ${ }^{47}$ y que, en cualquier caso es cuando menos incomprensible por parte del TC en la medida en que este art. 149.1.8 CE se esgrimía expresamente por el Abogado del Estado como uno de los títulos competenciales estatales conculcados por el legislador autonómico en relación con las asociaciones, tal y como figura en el Antecedente $2^{\circ}$ de la Sentencia.

En realidad, lo que ha sucedido, como bien señala Enrique LUCAS MURILLO DE LA CUEVA, es que la STC 173/1998 en este punto, le ha dado preferencia al art. 149.1.1 ${ }^{\circ} \mathrm{CE}$ : no se trata tanto de que el Estado pueda desarrollar una regulación jurídica del Derecho de asociaciones al amparo de sus competencias sobre legislación civil como de asegurar unas "condiciones básicas que garanticen la igualdad" en el ejercicio del derecho de asociación, aunque para ello use instituciones del Derecho civil. "Lo que le importa al Tribunal en este punto es esa garantía con independencia de que se instrumente a través de normas civiles, administrativas o mixtas, pues el título competencial aplicable no es el relativo a la legislación civil o a las bases de las repetidas condiciones básicas" 48 .

Y ésta es la pauta que, finalmente, ha seguido también el legislador, ya que la DF $1^{\text {a }}$ de la LORDA, en sus números 2, 3 y 4, establece los preceptos de directa aplicación en todo el Estado, por dictarse al amparo de las reglas $1^{\text {a }}, 6^{\mathrm{a}}$ y $14^{\mathrm{a}}$ del art. $149.1 \mathrm{CE}$, sin referencia alguna a la regla $8^{\mathrm{a}}$. Así resulta que muchas de las materias que, en principio, cabría entender alojadas en el concepto de "legislación civil" (art. 149.1.8 $\mathrm{aE}$ ) son de directa aplicación en todo el territorio, pero no por entenderse dictadas al amparo de este título, sino del 149.1.1 ${ }^{\circ} \mathrm{CE}^{49}$.

mentos públicos”, para determinar la interpretación auténtica del art. 5.3 de la Ley vasca, relativo a la cualidad pública o privada de los documentos del acta de constitución y los estatutos de la asociación.

47 Vid. Pedro de Pablo ConTreras, «La "legislación civil”...», cit., p. 1834. Denuncia que el TC ni siquiera valore la pertenencia de buena parte del régimen jurídico de las asociaciones a la "legislación civil", limitándose a cuestionar la legitimidad constitucional de la regulación autonómica mediante el examen de la reserva de Ley orgánica ex 81.1 CE así como de las competencias estatales deducidas del 149.1.1ํㅡㄹ $\mathrm{CE}$. En el mismo sentido, Amelia Pascual Medrano, "La Sentencia...", cit., p. 1863.

48 Vid. Enrique Lucas Murillo de la Cueva, Igualdad y autonomía..., cit., p. 146.

${ }^{49}$ Se establecía así una cierta contradicción entre la LORDA y la Ley de Fundaciones de 1994, coetáneas durante unos meses hasta la derogación de esta última por la nueva Ley 50/2002, de Fundaciones, ya que muchas de las cuestiones que la LORDA incluye bajo el 149.1.1 ${ }^{\circ} \mathrm{CE}$, la Ley 


\subsection{La competencia del Estado sobre "registros e instrumentos públicos" (art. 149.1.8 $\left.8^{\mathrm{a}} \mathrm{CE}\right)$}

Otro título competencial en principio intensamente implicado en el régimen jurídico de las asociaciones es el relativo a los "registros", que el art. 149.1.8 ${ }^{\circ}$ CE también reserva en exclusiva al Estado. Así, nuestro Derecho viene exigiendo tradicionalmente la inscripción de todas las asociaciones en un registro especialmente destinado a ellas ${ }^{50}$. De hecho, uno de los puntos más debatidos por la doctrina y la jurisprudencia desde la promulgación de la Constitución gira en torno a los efectos que, con respecto a la adquisición de personalidad por los entes asociativos, debe atribuirse a dicha inscripción.

Por esta causa, es lógico interrogarse acerca de hasta qué punto esta competencia "exclusiva" del Estado puede jugar aquí un papel decisivo en orden a sustraer este registro de asociaciones de la previsión y gestión de las Comunidades Autónomas. Es decir: ¿sólo el Estado, en virtud de este art. 149.1.8 $\mathrm{CE}$, es el poder público competente para llevar un registro de asociaciones?

Para responder a este interrogante, es necesario interpretar a qué tipo de registros se refiere la Constitución cuando habla de "registros públicos". Y es que tradicionalmente se han venido distinguiendo dos tipos de registros: los llamados "registros jurídicos" y los denominados "registros administrativos". La distinción no ha de recaer en criterios de tipo organizativo, según los cuales serían administrativos sólo los llevados por la Administración, porque prác-

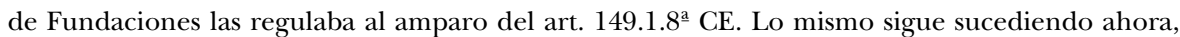
sin embargo, en líneas generales, con respecto a la nueva Ley 50/2002, de Fundaciones. Podría pensarse que el derecho de asociación posee una dimensión jurídico-pública más intensa por su configuración como derecho fundamental stricto sensu, lo que justificaría, a diferencia del derecho de fundación, su tratamiento exclusivo desde el título competencial del 149.1.1ํㅡ. Sin embargo, no debemos olvidar que el derecho de fundación, aunque no fundamental en sentido estricto, también se concibe por el art. $34 \mathrm{CE}$ como un derecho de libertad, al que precisamente se le extienden algunas de las garantías establecidas en el art. 22 CE para el derecho de asociación. Por eso, pensamos que la calificación del derecho de asociación como derecho fundamental en sentido estricto no debe implicar diferencias respecto del de fundación, al menos en lo que a la cuestión competencial se refiere.

${ }^{50}$ Ya la Ley de asociaciones de 30 de junio de 1887 preveía un registro especial llevado en el Gobierno de cada provincia, y en que debían inscribirse todas las asociaciones que tuvieran domicilio o establecimiento en dicha provincia (art. $7^{\circ}$ ). 
ticamente todos los registros en nuestro Ordenamiento han sido establecidos y encuadrados tradicionalmente en la Administración ${ }^{51}$.

El criterio de distinción más adecuado es el de la función que cumplen: serían "jurídicos" los registros destinados a dotar de certidumbre las relaciones jurídicas de los particulares, mientras que los "administrativos" estarían dirigidos más bien a la propia Administración, a proporcionarle información para el desarrollo de sus diversas funciones. De este modo, típicos ejemplos de registros jurídicos serían el Registro Civil, el de la Propiedad o el Mercantil, mientras que de registro administrativo sería buena muestra un registro de centros docentes no universitarios, con funciones fundamentalmente estadísticas u orientadas a políticas de fomento en el ámbito de la educación ${ }^{52}$.

Pues bien, ha precisado el $\mathrm{TC}^{53}$ que el art. 149.1.8 ${ }^{\circ} \mathrm{CE}$ se refiere más bien a los registros que aquí hemos denominado "jurídicos", correspondiendo su ordenación en exclusiva, por tanto, al Estado. La ordenación de los registros "administrativos", sin embargo, correspondería al Estado o a las Comunidades Autónomas según la distribución de competencias en la materia sobre la que los mismos incidan.

Sin embargo, la distinción no está exenta de numerosas dudas cuando descendemos al análisis del caso concreto. Así, se suele decir que los "registros jurídicos" son los que afectan a las relaciones jurídico-privadas, mientras que los "registros administrativos" se distinguen por no afectar a las mismas. Pero hay supuestos en que el Registro en cuestión reviste caracteres de ambas clases. Es el caso, sin ir más lejos, del propio Registro general (estatal o autonómicos) de Asociaciones. Bajo el régimen de la antigua Ley de asociaciones de

\footnotetext{
${ }^{51}$ Por ejemplo, es significativo que Adolfo POSADA dedicara la sección $\S 2^{0}$ del Capítulo V, 2 ${ }^{\underline{a}}$ Parte, de su Tratado de Derecho Administrativo, Madrid, 1898, pp. 166-174, al estudio del Registro de la Propiedad, al que consideraba como un "servicio de oficina" encuadrado en la "policía de la propiedad".

${ }^{52}$ Sobre las distintas clasificaciones ensayadas por la doctrina, así como de la imposibilidad de reducir a la unidad una teoría de la actividad registral de la Administración, vid., Germán FERNÁNDEZ FARRERES, Derecho de Asociación..., cit., pp. 327 ss. Sobre la naturaleza y funciones del Registro de la Propiedad, como paradigma de registro de "seguridad jurídica", puede consultarse la ya clásica obra de Ramón ROCA SASTRE, Derecho Hipotecario, Tomo I (Registro de la Propiedad), Bosch, Barcelona, 1954 (5 $5^{\underline{a}}$ ed.), pp. 16-18.

${ }^{53}$ Así, tempranamente, la STC 71/1983, de 29 de julio, refiriéndose a los "registros jurídicos" como "registros referentes a materias de Derecho privado".
} 
1964, dicho Registro no encontraba especiales dificultades de acomodo en la segunda categoría, en la "administrativa"; pero los determinantes efectos jurídicos que hoy la LORDA hace derivar de la inscripción en el mismo (alcance de la responsabilidad patrimonial, efectos para terceros de las modificaciones estatutarias, etc.), torna borrosa aquella nítida adscripción. Hasta tal punto han cambiado las cosas, que la doctrina no duda en afirmar que actualmente "la inscripción registral modula el régimen al que quedan sujetas las asociaciones en el tráfico jurídico, por lo que su funcionalidad, unida a la publicidad, termina vinculándose a la garantía de la seguridad jurídica" ${ }^{54}$. Pero si la configuración actual del Registro de Asociaciones responde más a la categoría del "registro jurídico" o "de seguridad jurídica" que al "meramente administrativo", ¿significa ello que las Comunidades Autónomas competentes en materia de asociaciones — por lo dispuesto en .el art. 149.1.8ํㅡㄹ C están desapoderadas para ordenar su propio Registro de Asociaciones, al menos con las características que aquí se han dibujado, debiendo inscribirse ahora todas las asociaciones sin excepción — también las constituidas al amparo de las leyes emanadas por Comunidades Autónomas con competencia en la materia- en el Registro estatal? Si se entendiera que la competencia exclusiva de algunas Comunidades Autónomas sobre asociaciones incluye la capacidad de ordenar registros con estas características, la distinción entre "registros jurídicos" y "administrativos" carecería de trascendencia a efectos prácticos - al menos desde el punto de vista competencial-: basta con que el Estado o la Comunidad Autónoma tengan competencias en la materia sustantiva que sea, para que tengan competencia sobre los registros (jurídicos o administrativos) que tengan por conveniente establecer en ese sector. En cualquier caso, lo cierto es que la LORDA, después de prever el Registro Nacional en su art. 25, establece taxativamente en el art. 26 que "en cada Comunidad Autónoma existirá un Registro Autonómico de Asociaciones, que tendrá por objeto la inscripción de las asociaciones que desarrollen principalmente sus funciones en el ámbito territorial de aquéllas". Este precepto es de los de directa aplicación en todo el territorio del Estado, por haberse dictado, según la DF 1aㅡ, al amparo del art. 149.1.1ํㅡㄹ CE. Estima así el legislador estatal que el Registro de Asociaciones, sea cual sea su ámbito, es de su exclusiva competencia, aunque, sorprendentemente no por ser materia de "registros públicos" (149.1.8을 $\mathrm{CE}$, sino por constituir una de las condiciones básicas que garantizan la igualdad de todos los españoles en el ejercicio de los derechos constitucionales (149.1.1ํㅡㄹ $\mathrm{CE}$.

\footnotetext{
54 Germán Fernández FARreres, Derecho de Asociación..., cit., p. 338.
} 
Por lo que se refiere a los "instrumentos públicos", la competencia exclusiva estatal es menos controvertida: así, la STC 173/1998 declaró que el 5.3 de la Ley vasca, que establece que el acta y los estatutos pueden contenerse en documento público o privado, no invade las competencias estatales en materia de ordenación de los instrumentos públicos si se interpreta, no como una libre opción ofrecida al ciudadano, sino como una remisión a las normas estatales que regulan los supuestos en que es necesaria la escritura pública (FJ $\left.14^{\circ} d\right)$.

\subsection{Otros títulos de competencia estatales concurrentes con el de las Comu- nidades Autónomas.}

Existen además otros títulos competenciales a favor del Estado que no versan directamente sobre la materia asociativa pero que sin embargo inciden de manera muy intensa en su régimen jurídico.

El primero de ellos es el relativo a la legislación procesal, que la CE reserva al Estado en el art. 149.1.6: "El Estado tiene competencia exclusiva sobre (...) legislación procesal, sin perjuicio de las necesarias especialidades que en este orden se deriven de las particularidades del derecho sustantivo de las Comunidades Autónomas". Es indudable que, de cara a acotar las competencias autonómicas respecto de las asociaciones, se ha de tener en cuenta que el Estado tiene competencia exclusiva en materia de legislación procesal, sin perjuicio de las especialidades que, en este orden, se derivan necesariamente de las particularidades del Derecho sustantivo de las Comunidades Autónomas. No parece que la regulación autonómica de un tipo asociativo concreto (obviamente, hasta donde las competencias autonómicas lleguen, según lo estudiado en epígrafes anteriores) en el contexto de una materia sobre la que la Comunidad Autónoma de que se trate tenga competencias, justifique de entrada la existencia de esas "particularidades del Derecho sustantivo de las Comunidades Autónomas" para que éstas entren a regular aspectos procesales relativos a dichas asociaciones ${ }^{55}$.

\footnotetext{
55 Así lo estimó en su momento, por ejemplo, el Consejo Consultivo de la Generalidad de Cataluña (Dictamen nº 144 del Consejo Consultivo de la Generalitat de Catalunya, de 15 de marzo de 1988, en Dictámenes del Consejo Consultivo de ..., cit., pp. 117 y 131-133) respecto de las asociaciones deportivas del Proyecto de Ley catalana del Deporte. Según el Consejo Consultivo, la acotación de competencias de la Generalidad sobre asociaciones deportivas viene dada, entre otros extremos, por el hecho de que el Estado tiene competencia exclusiva en materia procesal vía art. 149.1.6 ${ }^{\circ}$ CE. Concretamente, sostenía el Consejo que el art. 31 del citado Proyecto, que preveía que los acuerdos de los órganos de gobierno de las entidades deportivas contrarios al Ordena-
} 
En este sentido se pronunció también la STC 173/1998, en la que, tras afirmar su intención de delimitar las competencias estatales y autonómicas en conflicto con base en el art. 149.1. $6^{\circ} \mathrm{CE}^{56}$, declaró inconstitucional el art. 8.4 de la Ley vasca de Asociaciones ${ }^{57}$ en la medida en que invadía competencias estatales exclusivas sobre legislación procesal (art. 149.1.6ํㅡㄹ $\mathrm{CE}$ ) al establecer un cauce procesal específico (protección de los derechos fundamentales de la persona) para reaccionar frente al incumplimiento del plazo de inscripción y frente a la denegación de la misma por parte de la Administración. También tacha de inconstitucional el 12.3, en la medida en que regula la impugnación ante la jurisdicción de los acuerdos de los órganos de las asociaciones ${ }^{58}$ y establece un plazo para el acceso a los Tribunales, no el plazo de ejercicio de un derecho creado por la legislación autonómica, en cuyo caso sí habría entrado en juego la cláusula habilitante del 149.1.6 $6^{\circ} \mathrm{CE}$ ("sin perjuicio de las necesarias especialidades que en este orden se deriven de las particularidades del derecho sustantivo de las Comunidades Autónomas"). El mismo tratamiento recibe la frase "por la autoridad judicial" contenida en el art. 13.4: para el TC, que los libros de la asociación sean habilitados por la autoridad judicial ${ }^{59}$, su-

miento podían ser suspendidos, anulados o modificados por la autoridad judicial competente a "instancia de parte afectada" o "de las Administraciones deportivas", contenía sin duda una norma de carácter procesal. Y precisó que el tipo de legitimación contemplado no era comparable ni con los supuestos regulados en el Derecho procesal civil ni con los contenidos en la Ley Reguladora de la Jurisdicción Contencioso-administrativa. La competencia para regular, con el mayor alcance, un sector material como el deporte no comporta la génesis de especialidades procesales relativas a la legitimación procesal de la Comunidad Autónoma, aspecto intrínseco a la legislación procesal que corresponde al Estado.

56 Vid. FJ $6^{\circ}$.

${ }^{57}$ Decía así: "Contra el incumplimiento del plazo prescrito en el número 2, y contra la denegación de inscripción fundada en una causa distinta a la prevista en el número anterior, se podrán ejercer las acciones que sobre protección de los derechos fundamentales de la persona contemplan las leyes".

58 Dicho precepto establecía que "con independencia de eventuales responsabilidades penales, los acuerdos de los órganos de las Asociaciones podrán ser impugnados por cualquier socio, si los estimase contrarios a la Ley o los Estatutos, ante la jurisdicción civil ordinaria por los trámites del juicio que corresponda en aplicación de la Ley de Enjuiciamiento Civil. La acción caducará a los cuarenta días naturales, contados a partir de aquél en que el demandante hubiera conocido o tenido oportunidad de conocer el contenido del acuerdo impugnado".

${ }^{59}$ Reproducimos el tenor del precepto: "Como garantía de la efectividad de estos derechos y de los terceros que con ellas entablen relaciones, las Asociaciones llevarán un libro de registro de socios, un libro de actas y un libro de cuentas, que deberán ser habilitados al efecto por el Registro de Asociaciones o por la autoridad judicial, una vez se les haya notificado su inscripción registral". 
pone definir las atribuciones de los Juzgados y Tribunales, asignándoles funciones en garantía de derechos, y, por ello, corresponde sólo a la legislación procesal. Igual consideración ha merecido el art. 21 de la Ley vasca, pues, al discernir la competencia de los órdenes judiciales contencioso-administrativo y civil ${ }^{60}$, la ley autonómica establece una regla de competencia jurisdiccional que corresponde en exclusiva al legislador estatal mediante la Ley Orgánica del Poder Judicial (según establece el art. 122.1 CE), estándole vedada a la competencia en materia de asociaciones la posibilidad de regular la defensa jurídica de los derechos e intereses innovando el ordenamiento procesal ${ }^{61}$.

En esta línea, los artículos 39 a 41 de la LORDA, que deslindan las competencias entre los órdenes jurisdiccionales contencioso-administrativo y civil, así como el régimen de las diversas comunicaciones judiciales, todo ello en materia de asociaciones, se han dictado al amparo del art. 149.1.6 $6^{\circ} \mathrm{CE}$, como expresamente hace notar la DF $3^{\mathrm{a}}$.

Por otra parte, la LORDA también contiene otro grupo de preceptos al amparo de lo dispuesto en la regla 14 ${ }^{\mathrm{a}}$ del art. 149.1 CE: "El Estado tiene competencia exclusiva sobre: ... Hacienda General y Deuda del Estado". El ejercicio de esta competencia se ha concretado en los artículos 32 a 36 de la LORDA, que, junto a las DA1 ${ }^{\underline{a}}$ y DT $2^{\underline{a}}$, tienen la consideración de Ley ordinaria directamente aplicable en todo el Estado, "sin perjuicio de los regímenes tributarios forales vigentes en los Territorios Históricos del País Vasco y en la Comunidad Foral de Navarra". Dichos preceptos establecen el nuevo régimen jurídico de las asociaciones de «utilidad pública», y que tienen especial importancia para las medidas de fomento de que son objeto ciertas asociaciones especiales, como, por ejemplo, las de consumidores y usuarios.

Otras consideraciones planteadas a raíz del conflicto competencial resuelto por la STC 173/1998 consisten en determinar hasta qué punto juegan otros principios constitucionales que, sin realizar una distribución de competencias entre el Estado y las Comunidades Autónomas en sentido estricto, sí dejan sentir cierta influencia a la hora de abordar el estudio de estas cuestiones.

\footnotetext{
${ }^{60}$ Decía a este respecto el art. citado: "En todas las cuestiones que en vía administrativa se susciten sobre el régimen de Asociaciones será aplicable la Ley de Procedimiento Administrativo y, en su caso, la reguladora de la Jurisdicción Contencioso-Administrativa. En todas las demás cuestiones en que no sea parte la Administración, será competente la jurisdicción ordinaria, con aplicación, en su caso, de la Ley reguladora de la protección jurisdiccional de los derechos fundamentales de la persona”.

${ }^{61}$ Para todos estos supuestos, vid. FFJJ $14^{\circ}$.e y $16^{\circ}$.
} 
En efecto, establece el art. 139.1.CE que "todos los españoles tienen los mismos derechos y obligaciones en cualquier parte del territorio del Estado". Para el TC este precepto no es un título competencial, sino que reviste los caracteres de un principio que constituye presupuesto, límite o directriz que acota y guía el ejercicio de las competencias del Estado y de las Comunidades Autónomas. Enrique LuCAS MURILlo DE LA Cueva ha sintetizado así la doctrina del TC sobre este principio ${ }^{62}: 1$ ) la igualdad que persigue se predica de los ciudadanos y no de las Comunidades Autónomas; 2) no implica una identidad de regulaciones; 3) sólo opera dentro de cada ordenamiento autonómico en demanda de igualdad de trato ante él de todos los ciudadanos con independencia de su residencia y sin que ello excluya aquellas diferencias que tengan justificación razonable y objetiva conforme a la Constitución; 4) guarda una estrecha relación con la exigencia de una misma regulación de las posiciones subjetivas fundamentales en todo el territorio del Estado ex art. 149.1.1 ${ }^{\circ} \mathrm{CE}$; 5) su ámbito de aplicación se extiende a la noción de derechos y deberes constitucionales, más amplia que la de derechos fundamentales.

\subsection{Las cláusulas residual y de suplencia a favor del Estado (art. 149.3 CE) en materia de asociaciones; las llamadas asociaciones "de ámbito estatal"}

Finalmente, el art. 149.3 CE contiene dos cláusulas llamadas a desempenar un importante papel en la materia que estamos tratando. Se trata de la llamada "cláusula residual" de atribución de competencias a favor del Estado ("la competencia sobre las materias que no se hayan asumido por los Estatutos de Autonomía corresponderá al Estado..."); y de la llamada "regla de suplencia" según la cual "el derecho estatal será, en todo caso, supletorio del derecho de las Comunidades Autónomas".

Como es sabido, ésta segunda, la cláusula de suplencia, ha sido objeto de un lento proceso evolutivo en su interpretación por el TC, y que ha terminado por cristalizar en la doctrina según la cual se niega al Estado toda capacidad normativa en relación a materias que hayan sido asumidas por las Comunidades Autónomas en grado de homogeneidad. Como esta norma está, precisa el TC, dirigida al aplicador del Derecho, para los casos de laguna jurídica, pero en ningún supuesto entraña una suerte de título competencial "universal" a favor del Estado, éste no podría dictar una norma de carácter supletorio sobre materias que hayan sido asumidas por todas las Comunidades Autónomas de forma exclusiva, salvo que dichas normas vinieran justificadas en un tí-

\footnotetext{
62 Vid. Igualdad y autonomía..., cit., p. 67.
} 
tulo competencial estatal propio, es decir, o bien en uno de los contenidos en el 149.1 CE, o bien en una materia que le resultara atribuida por la vía de la cláusula "residual" (art. 149.3 CE) ${ }^{63}$.

Ahora bien, es precisamente en este segundo supuesto en el que se encuentra la materia asociativa. Como el Estado no carece de la facultad de dictar normas supletorias cuando, junto a Comunidades Autónomas plenamente competentes, existan otras Comunidades Autónomas que no lo son, las normas sobre asociaciones dictadas por el Estado para ser aplicadas en el territorio de estas últimas gozarán de eficacia directa respecto de las Comunidades Autónomas carentes de competencia; y respecto del territorio de las Comunidades Autónomas que, teniendo atribuida la competencia sobre asociaciones, no las hayan ejercido dictando las normas correspondientes -es el caso de Andalucía-, será el "operador jurídico" el que decida la eficacia supletoria de dichas normas para ese territorio ${ }^{64}$.

En definitiva, el legislador estatal, respecto a la materia asociativa -que es heterogénea desde el punto de vista competencial-, retiene la competencia exclusiva en relación a algunas Comunidades Autónomas por la vía de la "cláusula residual", mientras que para las Comunidades Autónomas que han asumido competencias sobre la misma materia en sus Estatutos de Autonomía juega la "cláusula de suplencia" 65 .

${ }^{63}$ Dicha doctrina, que se encuentra asentada en las conocidas SSTC 118/1996, de 27 de junio, y la 61/1997, de 20 de marzo, supone unos efectos altamente negativos para la seguridad jurídica. Vid., para un análisis crítico de esta nueva interpretación constitucional del 149.3 CE, entre otros, Eduardo GARCÍA DE ENTERRÍA, «La Sentencia constitucional 118/1996, de 27 de junio, sobre la Ley de Ordenación de los Transportes Terrestres de 1987 y sus implicaciones de futuro", Revista Española de Derecho Constitucional núm. 55 (1999), sobre todo pp. 259-261, y Curso de Derecho Administrativo, vol. I, Civitas, Madrid, 2000 (reimpresión 2001) (con Tomás-Ramón FERNÁNDEZ RODRÍGUEZ), pp. 351 ss; y Eloísa CARBONELL PORRAS, «La supletoriedad del Derecho estatal en la reciente jurisprudencia constitucional», RAP núm. 143 (1997), pp. 195 ss.

${ }^{64}$ En efecto, la determinación de la suplencia en este caso, según el TC, corresponde al "aplicador" del Derecho, es decir, a la Administración autonómica en primer término, no al legislador estatal; de tal forma que si un precepto estatal estableciera el alcance supletorio de sus normas respecto de esas Comunidades Autónomas, dicha disposición incurriría en vicio de inconstitucionalidad.

${ }^{65}$ Así lo hace notar, por ejemplo, Germán FERNÁNDEZ FARRERES, Derecho de Asociación..., cit., pp. 498 y 499. 
Por consiguiente, la normativa sobre asociaciones que el Estado dicte al amparo del título residual del art. 149.3 es aplicable: directamente en las Comunidades Autónomas con competencia únicamente de ejecución (Galicia, Principado de Asturias, Cantabria, La Rioja, Castilla y León, Aragón, Comunidad de Madrid, Castilla-La Mancha, Región de Murcia, Extremadura e Illes Balears), y supletoriamente (pero según el juicio del "operador jurídico") en las Comunidades Autónomas con competencia plena (Andalucía, País Vasco, Canarias, Comunidad Valenciana, Cataluña y Navarra).

La complejidad del sistema resultante salta a la vista y ha ocasionado que en este punto el redactor de la LORDA no se haya expresado con la claridad que sería deseable, máxime si tenemos en cuenta que dicha legislación es la llamada a partir de ahora a servir de canon a la producción normativa de las Comunidades Autónomas con competencias en la materia.

En cualquier caso, a la conclusión que apuntamos es a lo que parece que se ha querido referir la LORDA al emplear la confusa y defectuosa técnica le-

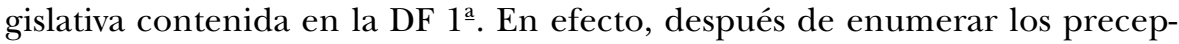
tos de la Ley que se dictan al amparo de los artículos 81.1 y $149.1 \mathrm{CE}$, y que son por tanto directamente aplicables en todo el territorio, establece que "los restantes preceptos de la Ley serán de aplicación a las asociaciones de ámbito estatal'. Sin embargo, ningún precepto de la LORDA define lo que debe entenderse por "asociación de ámbito estatal". Tan sólo la Exposición de Motivos, apartado IX, nos da una pista interpretativa cuando dice, explicando esta DF $1^{\mathrm{a}}$ :

"Las restantes normas de la Ley son sólo de aplicación a las asociaciones de competencia estatal, competencia que alcanzará a todas aquellas asociaciones para las cuales las Comunidades Autónomas no ostenten competencias exclusivas".

Es decir, que en la categoría de asociaciones de ámbito estatal se incluyen dos supuestos:

En primer lugar, los casos más normales, los que se deducen a contrario de lo expuesto por los Estatutos de Autonomía de las Comunidades Autónomas con competencia exclusiva sobre asociaciones: es decir, las asociaciones que no desarrollen principalmente sus funciones en una Comunidad Autónoma, sino en dos o más de ellas. Estas asociaciones, obviamente, son asociaciones de "ámbito estatal", porque rebasan el ámbito de una Comunidad Autónoma. 
Y en segundo lugar, están aquellos casos de asociaciones ubicadas en el territorio de una Comunidad Autónoma sin competencias exclusivas en materia de asociaciones: también éstas son "asociaciones de ámbito estatal", y también a ellas se les aplicará en su totalidad las normas contenidas en la LORDA. En otros términos: aunque la asociación desarrolle únicamente sus actividades en una Comunidad Autónoma, si ésta es de las que carecen de competencia exclusiva sobre asociaciones, dicha asociación será de "ámbito estatal" y se le aplicará la LORDA en su integridad ${ }^{66}$. Y obsérvese, en este sentido, lo inexpresivo e inapropiado que resulta referirse a estos supuestos con la locución "asociaciones de ámbito estatal".

Por el contrario, si la asociación desarrolla principalmente sus actividades en una Comunidad Autónoma de las que gozan de competencia exclusiva en materia asociativa, no será de "ámbito estatal", sino autonómico, y a ésta se le aplicará solamente el bloque de preceptos de la LORDA que tienen el carácter de Ley orgánica (por haber sido dictados al amparo del art. 81.1 CE) y de Ley ordinaria derivados de alguno de los títulos competenciales estatales del 149.1 CE. En todo lo demás, le será de aplicación la correspondiente normativa autonómica sobre asociaciones. Pero, de acuerdo con la doctrina expuesta arriba, de no existir esta última normativa por pura inactividad del legislador autonómico competente, le será de aplicación supletoria la normativa estatal aplicable en principio solamente a las asociaciones de ámbito estatal ${ }^{67}$, aunque dicho juicio de suplencia —según doctrina del TC— corresponderá al aplicador del Derecho, y no al legislador estatal (razón por la cual la LORDA no contiene ninguna previsión al respecto).

\section{CONCLUSIÓN}

A modo de recapitulación, y a diferencia de las normas aprobadas por las Comunidades Autónomas que no tienen competencia "exclusiva" sobre asociaciones, la Ley andaluza podría extenderse a todos los aspectos del régimen jurídico general de las asociaciones andaluzas, siempre y cuando respete los severos límites que le imponen las competencias del Estado ex artículos 81 y 149.1.1 ${ }^{\circ} \mathrm{CE}$ ya analizados.

\footnotetext{
${ }^{66}$ Sobre la interpretación de esta DF $1^{\underline{a}}$ LORDA, vid. Manuel PANIAGUA ZURERA, «Las repercusiones de la Ley orgánica 1/2002, de 22 de marzo, reguladora del Derecho de Asociación, en la normativa estatal sobre asociaciones de consumidores y usuarios", Estudios sobre Consumo núm. 64 (2003), p. 99, también en este sentido.

${ }^{67}$ En este sentido, vid., Germán FERNÁNDEZ FARRERES, Derecho de Asociación..., cit., pp. 499.
} 
Ciertamente, el margen de maniobra que finalmente deja la LORDA a las Comunidades Autónomas con competencia "exclusiva" no es muy amplio, aunque alcanza a aspectos tan importantes como el régimen interno de las asociaciones, el régimen de sus actividades, ciertas obligaciones documentales y contables (relación de asociados, libro de actas y de contabilidad, etc.), el régimen aplicable a las modificaciones estatutarias, la liquidación de la asociación, el establecimiento de canales concretos de participación administrati$\mathrm{va}^{68} \ldots$ Y sobre todo ello -insistimos- la Comunidad Autónoma podría acometer una regulación general de las asociaciones sometidas a su competencia, y no una ordenación meramente subordinada u orientada a la concesión de ayudas y subvenciones ${ }^{69}$.

${ }^{68}$ Extremos todos ellos contenidos en preceptos de la LORDA que entendemos han sido dictados por el Estado al amparo del art. 149.3 CE (DF 1 a .5).

${ }^{69}$ A diferencia de las Comunidades Autónomas con competencias únicamente de "ejecución" sobre asociaciones, que no pueden dictar normas generales sobre asociaciones, sino únicamente normas sectoriales sobre materias de su competencia (juventud, deporte, tiempo libre, asistencia social, agricultura...), y que sólo indirectamente podrán tener alguna incidencia sobre las asociaciones que operen en esos sectores. Dichas normas sobre asociaciones tan sólo tendrán el carácter de preceptos sectoriales referidos a materias en las que inciden otros títulos autonómicos de competencia, de modo que esa regulación se limitará por lo general a establecer los requisitos que deben cumplir las asociaciones para acceder a las ayudas previstas por la Comunidad Autónoma en ese sector. No se podrán entender, en consecuencia, a modo de regulación general de las asociaciones juveniles, deportivas, de ocio, de voluntariado, agrarias, etc. Vid., a este respecto, la STC 157/1992. En este pronunciamiento el TC resuelve un conflicto positivo de competencia planteado por el Gobierno de la Nación frente al Consejo de Gobierno de Islas Baleares, que con su Decreto 29/1985, de 18 de abril (BO Islas Baleares de 10 de mayo, núm. 13), había aprobado una serie de normas sobre constitución y funcionamiento de asociaciones juveniles. La Comunidad Autónoma poseía competencias en materia de juventud, pero carecía de facultades en relación con la materia asociativa. El problema consistió en que el Consejo de Gobierno, haciendo uso de aquéllas, pero no de éstas (de las que carece), dicta un Decreto regulando diversos aspectos de las asociaciones juveniles que en opinión del TC superaban con mucho las posibilidades que brindaba la competencia sobre juventud. La STC 157/1992, que da la razón al Estado, puede resumirse en los siguientes puntos: 1) En primer lugar, la competencia autonómica sobre la materia juventud justifica que la Comunidad Autónoma regule aspectos relacionados con las asociaciones cuyos fines y actividades coincidan con esa materia, sobre la que tiene competencias la Comunidad Autónoma; 2) Esta capacidad de la Comunidad Autónoma pasa sobre todo por la posibilidad de realizar actividades de fomento de las asociaciones juveniles, que no tienen por qué limitarse únicamente a una mera actuación administrativa de concesión de subvenciones y ayudas, sino que también puede incluir la regulación de las condiciones que deben poseer las asociaciones para poderse acoger a los beneficios que decida establecer la Comunidad Autónoma; 3) Sin embargo, precisa el TC que esa regulación tiene dos importantes límites: no debe incidir en el desarrollo del derecho de asociación (que está reservado a la Ley orgánica por el art. 81.1 CE) ni establecer el "régimen jurídico general" de las asociaciones radicadas en la Comunidad Autónoma. Sobre aquél, porque es un aspecto reservado a legislador orgánico —y por ende estatal(art. $81 \mathrm{CE}$ ); sobre éste, porque la Comunidad Autónoma balear no tiene atribuida —a diferencia de otras Comunidades Autónomas- la competencia normativa sobre asociaciones. 
En cualquier caso, conviene recordar que la reserva de ley efectuada por el art. 53.1 CE también vincula a la Comunidad Autónoma. Y aunque sólo se extiende al "ejercicio" del derecho de asociación, respetándose en todo caso "su contenido esencial", hemos de tener en cuenta que muchos de los aspectos del régimen jurídico de las asociaciones enumerados inciden más o menos directamente en dicho ejercicio. Así sucede, por ejemplo, con el registro de asociaciones, que, dependiendo de los principios con que se regule y los efectos jurídicos (constitutivos o declarativos de la existencia de la asociación, por ejemplo) que se hagan depender de la inscripción en el mismo, puede ejercer una decisiva influencia en el ejercicio del derecho de asociación ${ }^{70}$.

Finalmente, las competencias de ejecución se extienden, básicamente, a la inscripción de las asociaciones en el Registro de asociaciones de Andalucía, así como a llevar a cabo las correspondientes actuaciones de coordinación y comunicación con los órganos competentes del Estado en esta materia ${ }^{71}$. También podrían extenderse a la puesta en marcha e impulso constante de distintos canales de participación administrativa, en los que las asociaciones podrían asumir un papel protagonista, a la manera en que el Estado, en su propio ámbito, ha decidido establecer ${ }^{72}$.

\footnotetext{
70 No en vano el art. 26 LORDA, que lo prevé para las distintas Comunidades Autónomas, ha sido dictado al amparo del art. 149.1.1 ${ }^{\circ}$ CE (DF 1 a .2 ). En este sentido es reseñable el Decreto 152/2002, de 21 de mayo, por el que se aprueba el Reglamento de organización y funcionamiento del Registro de Asociaciones de Andalucía (BO Junta Andalucía de 13 de junio de 2002, núm. 69), adscrito a la Dirección General de Instituciones y Cooperación con la Justicia de la Consejería de Justicia y Administración Pública (art. 2). Esta normativa no vulnera la reserva de Ley del art. 53.1 CE porque puede entenderse que no es más que el desarrollo reglamentario del citado art. 26 y demás preceptos concordantes de la LORDA.

${ }^{71}$ Como hemos señalado, el art. 26 LORDA obliga a las Comunidades Autónomas a llevar un Registro de las asociaciones que caen bajo su competencia. Este precepto impone la obligación de que los distintos Registros autonómicos comuniquen al Registro Nacional los asientos de inscripción y disolución de las asociaciones de ámbito autonómico.

72 Así, por ejemplo, el art. 42 LORDA prevé la creación de distintos Consejos Sectoriales de Asociaciones, como "cauce de participación ciudadana en asuntos públicos" en relación con los "distintos ámbitos de actuación". Tanto en la legislación del Estado como en la andaluza existen ya órganos de participación en los que se integran asociaciones de diverso signo. Podemos citar, como ejemplos, el Consejo de los Consumidores y Usuarios, que integra a las asociaciones de consumidores y usuarios y se halla previsto en el art. 22.5 LGDCU. El Decreto 514/1996, de 10 de diciembre, crea el Consejo de los Consumidores y Usuarios de Andalucía, órgano similar al estatal en el ámbito de Andalucía, y el art. 25 de la Ley andaluza 7/2001, de 12 de julio, del Voluntariado, prevé el Consejo Andaluz del Voluntariado, en el que se integran entidades que desarrollen programas de acción voluntaria, que han de estar legalmente constituidas, dotadas de personali-
} 
Lógicamente, la competencia ejecutiva también incluye la concesión de los beneficios, así como la fiscalización de los requisitos correspondientes, en que la actividad de fomento autonómica se haya concretado. En este sentido, además de las actuaciones de colaboración con el Estado que a la Administración andaluza le competen en relación con el otorgamiento de la declaración estatal de «utilidad pública» ${ }^{73}$, se encargará de la ejecución de las medidas o declaraciones equivalentes que en su caso pudieran establecer en el ámbito de sus competencias ${ }^{74}$.

dad jurídica y carecer de ánimo de lucro -es decir, asociaciones o fundaciones, fundamentalmente- (art. 13.1). Aunque realmente en algunos de estos casos es muy posible que entren en juego aquí, más que la competencia sobre asociaciones, otros títulos competenciales autonómicos o estatales (defensa de los consumidores y usuarios, asistencia social...), junto al ejercicio de la potestad de autoorganización correspondiente.

${ }^{73}$ La declaración de «utilidad pública» consiste en una calificación jurídico-administrativa de la que se derivan ciertas ventajas, sobre todo de orden económico. Desde esta perspectiva, la declaración de utilidad pública no es más que una medida de fomento, otra más de las que las asociaciones pueden ser objeto. De hecho, la normativa estatal que actualmente regula esta figura con carácter general se encuentra recogida en los artículos 32 a 35 LORDA, dentro de su Capítulo VI que lleva por rótulo "Medidas de fomento". Por ello, podríamos aplicar aquí la conocida doctrina del TC según la cual la competencia de fomento en un determinado sector existirá en la misma medida en que exista a su vez una competencia material sobre dicho sector. De esta manera, tanto el Estado como las Comunidades Autónomas serían competentes para establecer este beneficio respecto de las asociaciones que correspondan a sus respectivos ámbitos de competencia. Sin embargo, como esta declaración conlleva importantes beneficios de carácter fiscal para las asociaciones sobre las que recae aquélla, los citados artículos 32 a 35 de la LORDA son directamente aplicables en todo el territorio nacional al haberse dictado con base en el art. 149.1.14 $\mathrm{CE}$ ("Hacienda Pública") (DF 1a.4). Ello no impide, ante las competencias que sobre asociaciones retienen las Comunidades Autónomas, que el Estado prevea los mecanismos de coordinación y colaboración más adecuados para el ejercicio de las que les corresponden a él. Así, la Junta de Andalucía es la Administración receptora de las solicitudes de declaración de «utilidad pública» respecto de las asociaciones de su competencia, aunque deberá remitir los expedientes, con su informe-propuesta, al Ministerio del Interior, que es el órgano competente para la resolución [vid. art. 3 RD 1786/1996, de 19 de julio, sobre procedimientos relativos a asociaciones de utilidad pública, y Anexo I, B) 5 del RD 304/1985, de 6 de febrero, de Traspaso de funciones y servicios del Estado en materia de asociaciones a la Junta de Andalucía].

${ }^{74}$ Por ejemplo, las asociaciones canarias pueden recibir de su Comunidad Autónoma la declaración de «interés público de Canarias» (art. 38 Ley canaria 4/2003, de 28 de febrero, de Asociaciones de Canarias). Similar declaración pueden obtener las asociaciones vascas de su Gobierno autonómico (art. 22 de la Ley 3/1988, de 12 de febrero, de Asociaciones de Euskadi). Sobre estos beneficios, vid. Víctor Angoitia Gorostiaga, «Breves consideraciones en torno a la personalidad jurídica, responsabilidades, utilidad pública y disolución de las asociaciones en la Ley vasca 3/1988, de 12 de febrero", Derecho Privado y Constitución núm. 9 (1996), especialmente pp. 35 ss. 